\title{
Goizuetako 1753ko sermoia: edizioa eta azterketa The Goizueta sermon of 1753: edition and analysis
}

\author{
Urtzi Reguero Ugarte \\ UPV/EHU - Aziti Bihia
}

\begin{abstract}
In this work, we present a philological edition of a sermon written in 1753 in Goizueta (Navarre). In addition, we have done a language analysis of the most interesting dialectological and historical characteristics of the text. To end with, we demonstrate that this text could be an evidence of a Basque variant spoken in Goizueta.
\end{abstract}

Keywords: sermon, old texts, dialectology.

\section{Laburpena}

Saio honetan 1753 an Goizuetan idatzitako euskarazko sermoi baten edizioa eta hizkuntza-azterketa dakartzagu. Edizioa filologikoa da eta testua bere osotasunean ulertzen laguntzeko oharrak ditu. Bestetik, hizkuntza-azterketan dialektologiaren eta hizkuntzaren historiaren aldetik interesgarri diren ezaugarriak aztertu ditugu. Ondorioetan Goizuetako orduko euskararen lekukotasuna izan daitekela erakutsi dugu.

Hitz gakoak: sermoiak, testu zaharrak, dialektologia.

\section{Sarrera ${ }^{1}$}

Ezin ukatu: Internetek berebiziko ekarpena egin dio filologiari; batez ere, artxibo eta liburutegietako agiri zaharrak digitalizatzeari esker, ezagutzen ez genituen eta urteetan ezkutatuta egon diren testu zaharrak agertu dira, eta asko inoiz baino eskuragarriago daude euskalari eta filologoontzat (ik. Bilbao 2013 eta Bilbao \& Gómez 2014).

Oraingoan dakargun sermoi hau kasualitatez aurkitu genuen sarean tesirako gauzak bilatzen, kuskusean genbiltzala Eusko Legebiltzarraren Liburuklik atarian. ${ }^{2}$ Jato-

\footnotetext{
1 Artikulu hau UFI11/14 erreferentziadun UPV/EHUko formazio eta ikerketa taldearen eta MINECOk finantzatutako "Monumenta Linguae Vasconum (IV): textos arcaicos vascos y euskera antiguo" (kodea: FFI2012-37696) proiektuaren baitan egina da. Eskerrak eman behar dizkiet Aziti Bibia-ko kideei eta, bereziki, Eneko Zuloagari, Dorota Krajewskari eta Ekaitz Santaziliari, eta Ricardo Gómezi egindako ohar ezin baliagarriagoengatik.

${ }^{2}$ Estekaren erreferentzia zehatza: http://www.liburuklik.euskadi.net/handle/10771/8477 [Azken kontsulta: 2016/02/06].
} 
rrizkoa egun Eusko Legebiltzarreko artxiboan dago, baina ez dugu zuzenean ikusteko aukera izan.

\section{Testuaz: urtea, egilea eta egitura}

Lekukotasun honek zehaztasun osoz erakusten digu noiz eta norako idatzi zen. Sermoi honen izenburuan bertan esaten denez, badakigu Goizuetan 1753ko Ostiral Santuan irakurri zela. Oker ez bagaude, urte hartan apirilaren 22an egokitu zen Ostiral Santua. Areago, egunaz gain, badakigu arratsaldeko hiruretan irakurtzeko prestatu zela sermoia (ik. 7. oin-oharra).

Haatik, testuaren egilea nor zen ez da agertzen eskuizkribuan. Ez dakigu, beraz, nor zen testua idatzi eta irakurri zuena. Dena dela, litekeena da Goizuetako apaiza bera izatea egilea.

1753. urtean, Vatikanoaren eta Espainiako Erreinuaren artean konkordatu bat sinatu zuten, eta azken hau atera zen irabazten bestearen kaltean. Horren ondorioz, Espainiako errege Fernando VI.ak, zeukan boterearen erakutsi nahian, ongi jaso nahi izan zituen elizbarruti bakoitzari zegozkion eliza, parrokia, komentu eta bestelako jabetzak zein ziren eta horietan arduradun nor zen (Prada et alii [s.a.]). Nafarroaren kasuan, Iruñeko Elizbarrutiko Artxiboan gordetzen da informazio hori guztia dakarren eskuizkribua, eta bertan, Goizuetari dagokionez, ondoko hau dator: «Es abad de la Real Iglesia Colegial de Roncesvalles, y vicario don Juachin de Alduncin», Teresa Alzugaray ${ }^{3}$ Iruñeko Elizbarrutiko Artxiboko arduradunak jakinarazi digunez, Goizuetako garai hartako prozesuak begiratuta Joakin Ignazio Alduntzin zen bertako bikario, baina ez da parrokoaren berririk; beraz, badirudi Alduntzinek zuela parrokiaren ardura osoa. Gainera, prozesuetako batean parrokiako lanak egiteko laguntzailerik ez izatea egozten zaio. Bikarioak meza eman dezakeenez, zilegi da, beraz, Alduntzin izatea sermoiaren egilea. Nolanahi ere, hipotesi hau baiezta edo ezezta liteke, beharbada, Goizuetako eliz artxiboko orduko agirietan begiratuta.

Sermoiaren egituraz den bezainbatez, sarreraz gain, hiru ataletan bereizita dago. Oro har, testuak Jesukristoren heriotzak Maria Ama Birjinarengan eragindako minaz dihardu, eta min hori hirutan banatzen du: aitaren galera, senarraren galera eta semearen galera. Min bakoitzari atal bat eskaintzen dio sermoilariak: «Eta iru soledade oien rigoreac izanen dira gaur nere asumptoco iru puntu brebeac» (4r). Atal bakoitzaren izenburuetarako, Bernardo Clairvauxkoaren idatziez baliatu zela dirudi. Hain zuzen ere, sermoian latinez agertzen da Tu mibi Pater, tu mihi sponsus, tu mibi filius, tu mihi omnia eras. Nunc orbor Patre, viduor sponso, desolor filio, omnia perdo dator; eta Bernardo Clairvauxkoaren hitzak dira ondokoak: «Tu mihi Pater, tu mihi mater, tu mihi sponsus, tu mibi filius, tu mihi omnia eras. Nunc orbor Patre et Matre, viduor sponso, et desolor prae omnibus, omnia perdo» (ik. 17. oin-oharra).

Horrezaz landara, paragrafoak zenbatuta daude, orotara, hogeita hamar. Hala ere, orrialdeak ez daude zenbatuta; beraz, gure edizioan dauden zenbakiak guk jarritakoak dira.

3 Bihoazkio hemendik eskerrak hari. 
Sermoilaria elizgizona zen neurrian, gizon jantzia zela dirudi, bai bederen teologia gaietan. Ikusiko denez, Itun Zaharreko esanak ongi erabiltzen ditu, Ostiral Santuko gertakarietan txertaturik. Gainera, bestelako testu erlijiosoak ere ezagutzen ditu.

\section{Zenbait ohar XVIII. mendeko sermoigintzaz Nafarroa Garaian}

Gaiak ikerketa sakonagoa merezi badu ere, esan liteke Xviır. eta, batez ere, XIX. mendeetako euskarazko literatur tradizioan, uler bedi literatura bere esanahi zabalenean, sermoiek leku beregaina dutela. Euskal Herrian hainbat dira denbora hartan, han eta hemen, predikatzen aritu ziren elizgizonak. Zuloagak (2010, 2011), esate baterako, Bizkaiko Nerbioi ibarrean XVIII. mendearen bukaeran eta XIX. mendearen hasieran sermoigintzan aritu ziren Bizente Sarriaren eta Juan Ignazio Astigarragaren sermoiak aztertu ditu; Ulibarrik (2015) sermoiez osaturiko dotrina baten edizioa aurkeztu berri du.

Nafarroa Garaiari dagokionez, ia mendearen hastapenetatik ugari dira gugana iritsi diren euskarazko sermoiak. Data ezaguna duen sermoirik zaharrena $1729 \mathrm{koa}$ da (Ondarra 1981) eta, Otsagabian agertu arren, hegoaldeko goi-nafarreraz idatzia dago. Halaber, lagin gisa aipa litezke 1743 ko beste bi sermoi anonimoak (Satrustegi 1987), Muruzabalgo bilduman jasoak, eta multzo berean dago orain arte argitaratu gabe dagoen 1748ko sermoia ere. Hain zuzen ere, Satrustegik (1987) ezagutzera emandako bilduma hartan, arestian aipatutakoez gain, egile ezezaguneko beste hainbat sermoi daude. Batzuetan urtea badakigu, besteetan ez. Horietako asko Langarikak jaso zituen, XVIII. mendearen bigarren erdialdean, handik eta hemendik, eta beste batzuk berak kopiatuak dira (Satrustegi 1987: 140). Sail berean, badaude Satrustegik Euskal Testu Zaharrak II bilduma amaitu gabean sartu nahi izan zituen beste hainbat sermoi, noiz argia estaltzen dioten trabak kendu zain. Horiezaz landara, Ondarrak (1989, 1993b, etab.) xviII. mendeko egile ezezaguneko sermoi andana eman zuen ezagutzera, eta berriki XVIII eta XIX. mendeko Nafarroako zenbait sermoi argitaratu ditu Lekarozek (2006, 2014, 2015).

Gugana iritsi diren sermoi asko anonimoak izan arren, ezagutzen ditugu sermoiak edo predikuak idatzi zituzten idazleak, besteak beste hauek: Martinez Morentingoa, Martin Markotegi, Juan Iberokoa, Sebastian Mendiburu, Joakin Lizarraga Elkanokoa eta Miguel Ignacio Armasa.

Jimeno Juriok (2004:150-151) gogorarazten duenez, orduko Nafarroan literatura landu zuten idazleak elizgizonak izan ziren; eta helburu garbi bat zuten: herritarrei erlijiozko heziketa ematea eta deboziozko praktika erakustea. Horren ondorio da XVIII. mendeko dotrina eta sermoi andana. Dirudienez, beraz, tradizio horretan kokatu behar da Goizuetako 1753ko hau ere.

\section{Edizio honi buruz}

Ondoren aurkeztuko dugun edizioak kritikoa izan nahi du; kritikoa Ordunak (1990: 21) adierazten duen zentzuan, alegia, testua ongi ulertzeko egin beharreko zuzenketa eta oharrak eginda.

Hori dela eta, testuak bi motatako oharrak izango ditu. Batetik, ohar paleografikoak izango ditu, erreferentzia egiten dion hitza biribilez idatzia eta kortxete batek 
ixten duela. Bertan testuan egon daitezkeen hutsen, lerro arteko erantsien eta irakur ezin daitezkeen zatien berri eman dugu. Bestetik, ohar azalgarriak ditu. Horietan testuan agertzen diren pertsonaia, gertakari, Bibliako pasarte eta bestelakoen argibide eta itzulpenak eman ditugu, testua ulertze aldera irakurketa erraz dezaketelakoan. Latinez dauden pasarteen euskarazko ordainak Elizen Arteko Biblia liburutik atera ditugu.

Grafiaz den bezainbatez, eskuizkribukoa mantendu dugu, aldaketa handirik egin gabe. Halere, letra larri eta xeheen erabilera eta puntuazioa egungo erabilerara egokitu eta euskarazko testuan agertzen diren laburdurak osatu ditugu, oharrik eman gabe. Hauek dira testuan agertzen diren laburdurak: Xptô $\rightarrow$ Christo; Jph $\rightarrow$ Joseph; Ess. ${ }^{r a} \rightarrow$ Escritura; Srâ $\rightarrow$ Señora; Mag. ${ }^{a} \rightarrow$ Magestadea; pnte $\rightarrow$ presente; dhoso $\rightarrow$ dichoso. Osatu ez dugun laburdura bakarra sermoiaren izenburuan dagoen Cap. (kapitulu) da. Hitzen banaketa ere eguneratu dugu, inolako aldaketa morfonologorikorik gertatu ez den kasuetan. Beraz, aditudut $\rightarrow$ aditu dut, baina etzara $\rightarrow$ etzara . Kasu batean gab illuna agertzen da, bereiz baina bilakabide fonologiko begi bistakoarekin; hori horrela utzi dugu. Amaitzeko, eskuizkribuaren orrialdeek ez dute zenbakirik, baina guk gurean hori gehitu diegu erreferentzia izan dezagun.

\section{Testua}

$<1$ r $>$ Sermón de la soledad de la Virgen María y descendimiento de la cruz, predicado el día Viernes Santo, a las tres horas de la tarde, en la parroquia de la villa Goizueta, el presente año de 1753.

$<3$ r Stabat juxta crucem Jesu mater ejus. ${ }^{4}$ Joan. Cap. 19.

Josseph autem mercatus sindonem, et deponens eum, involvit sindone, et posuit eum in monumento. ${ }^{5}$ Marc. Cap. 15.

1. Egun ${ }^{6}$ artu dut noticia bat guztiz melancolicoa eta tristea. Aditu dut esaten parage onetatic juduac embidiaz quendu diotela bicitza Jesus Nazareno deitcen zaion guizon justo propheta santu bati, cela guizon au Maria deitcen zaion andre doncella, escogitu, prudenta virtute guciac berequin dituen baten seme bacarra. Dauca noticia onec gaur nere bihotz gucia penatua, congojatua, angustiatua ta illundua. Nola iduqui al dezaque bere ama maitearena? Ha, nere ama bacar beracha! $\mathrm{Zu}$ bide zara seme orren ama. Bai, ama desamparatua, ezaguna zaude zure soledadean, zure penan, zure congojan, zure tristezan, zure lutuan eta zure beguietaco malcoetan. Esadazu, ama afligitua: cer eguin da zure beguietaco arguia, zure bihotceco consueloa, zure animaco fortaleza, nora da zure seme Jaincoa? Ay, noticia cruela, baña ciertoa! Yl da, eman du bere bicitzaren atceneco asnasea ostiral batean

\footnotetext{
4 Stabat... mater ejus: «Jesusen gurutzearen ondoan zeuden haren ama, amaren ahizpa, Maria Kleofasen emaztea eta Magdalena Maria» (Jn 19, 25). Ohar gaitezen Bibliako jatorrizkoan lau emakume daudela Jesusen ondoan, baina hemen sermoigileak Ama Birjina bakarrik dagoela dio.

5 Josseph... in monumento: "Honek [Josek] izara bat erosi eta, Jesus gurutzetik eraitsirik, izaran bildu zuen eta haitzean zulaturiko hilobi batean ezarri» $(\mathrm{Mk} 15,46)$.

6 Egun: ezbairik gabe Ostiral Santuaz ari da.
} 
arratsaldeco iru orduetan. ${ }^{7} \mathrm{Yl}$ da etsai sacrilegoen escu cruelen artean, gurutceco ogue gogorrean, afrenta andiarequin, pueblo guciaren aurrean, iru ilcetatic chinchillica. Yl da recebituric buruan aranzazco coroa, beguietan istuac, bearrietan afrentac, agoan beazumarequin vinagrea ${ }^{8}$ matralletan bofetadac, bizarrean tiracac, lepoan soca cateac, solbardan gurutcea, espaldetan azoteac, escu-oñetan zuloac, miembroetan ezur partitceac, biotcean tristezac, entrañetan icarariac, eta guelditcen dela gucia heritua, lastimatua, llagatua oñetic bururaño, â planta pedis usque ad verticem capitis non est in eo sanitas. ${ }^{9}$ Allegatu da ematera bere bicitzaren atceneco asnase dulcea. Yl da gure amorioan gucia abrasatua, arcen dituela bere gain gure eritasunac eta eriotza, gozatceagatic guc osasuna ta bicitza, vere langores nostros ipse tulit, et dolores nostros ipse portavit. ${ }^{10}$

2. Negar eguizute nerequin, catholicoac, negar eguizute gaur. Suspira zazute suspiro tiernoaquin, $<3 \mathrm{v}>$ lamenta zazute ay ${ }^{11}$ tristeaquin. Badugu motivoa gure bihotzac sentimentuz ${ }^{12}$ urturic despeditceco beguietatic malcotan, gure ternurac publicatcen dituela sentimenturic andienac, marmolic gogorrenac, sentimentu utsaz puscatcen diranean eta ceruac estalcen diranean lutuz, illuntasunaz ${ }^{13}$ ta lañoz. Eguzquiac ucatcen derazquiola munduari bere edertasunac, augmentatcen ditu illuntasunen ${ }^{14}$ horroreac. Ceruco ateac despedituric beren toquietatic, pedazatcen dira violencia andiaquin. Arriac partitcen dira. Lurra icaratcen ta idequitcen da. Templo santuco veloa arrascatcen da eta, enfin, sentidoric eztuten criatura guciac ere, sentidoa bailute bezala, sentimentuaren eta penaren pasioz nai luquete acabatuac izan beren creadorearen eriotzarequin.

3. Ay, doncella soberana! Ya ez dezaquet gueiago continua escatu bague zure gracia eta, tocatcen zaiolaric gaur arratsaldean nere oztasunari (villa noble onen piedadearen devocioa nere ignoranciac desempeńatceco) ponderatcea zure soledadea, zure bacartasuna, zure desamparoa, andiagoa da nere dificultadea eta gueiagocoa ${ }^{15}$ ne-

7 iru orduetan: Itun Berrian Mateo eta Markos ebanjelarien arabera (Mt 27, 45-50; Mk 15, 33-38), Jesus arratsaldeko hirurak aldera hil zen. Ordu hartan «Ene Jainko, ene Jainko, zergatik utzi nauzu?» esan bide zuen. Ez dirudi kasualitatea denik, beraz, sermoi hau Ostiral Santuko arratsaldeko hiruretako mezan irakurri izana.

8 agoan beazumarequin vinagrea: 'ahoan beazuma eta binagrea', "Xrekin Y» egitura kopulatibo zaharra da (ik. \$5.4.1). Ebangelioen araberan (Mk 15, 36; Mt 27, 48; Jn 19, 29), Jesus gurutzean zela ikusleetako batek belaki bat ozpinetan busti eta kanaberan loturik edateko eman zion.

9 à planta... eo sanitas: "Orpotik burura, ez duzue atal bat ere osorik» (Is 1, 6). Sermoian Jesukristori buruz ari bada ere, Itun Zaharrekoa da pasartea. Hain zuzen ere, Jainkoak Amotzen seme Isaiasi Juda eta Jerusaleni buruz eman zion mezuan agertzen da.

10 vere... ipse portavit: «Baina gure gaitzak hartu zituen bere gain, gure oinazeen zama jasan» (Is 53, 4). Hau ere Itun Zaharretik hartua da, eta Isaiasek Jauna berriro Jerusalenekin adiskidetu zenekoa kontatzen du.

11 ay: Ez dirudi hemen interjekzioa denik, izena baizik. OEHk (s.v. ai 2) 'intziri, auhen' hitzen sinonimotzat dakar. Ohart gaitezen, gainera, Axularren Gero liburuaren bigarren argitalpeneko ale bati goinafarreraz egindako ohar batean «auhenen eta dolamenen» «aien eta doloreen» aldatu zutela (Los Arcos 1974).

12 sentimentuz] esk. sentimentut.

13 illuntasunaz] esk. illuntasunac; hutsa bide da aurreko eta ondokoak ikusita.

14 illuntasunen] eskuizkribuan irakurketa garbia da, baina usus scribendian oinarritzen bagara, badirudi illuntasunean behar lukeela.

15 gueiagocoa] esk. gueiacoa. 
cesitatcen dudan gracia. Presente iderotcen zara nai badidazu asistitu. Ez dut uste gaur, zure gracien iturri guciac idequiagoac dauden temporan, ucatuco didazula desempeñatceco gracia. Graciaz betea zara, bana zazu zure gracia andi orren tanta bat gure bihotcetara, gure animetara. Ea, nere ama maitea, nere penen consueloa, nere empeñoen desempeñoa, ezcaitzatzula arren desampara. Lagun zaguzu, asisti zaguzu, obliga dezagun, cristabac, salutatcen dugula aingueruac bezala, eta gaurco ocasio triste tiernoari dagocan bezala, esaten diogula: «Ave Maria, graciaz betea, gaur penaz betea, Jauna da zurequin, gaur dago gurutcean defuntu, bedeicatua zara zu andre gucien artean, gaur afligituena zara zu andre gucien artean, ta bedeicatua da zure sabeleco frutua Jesus. Gaur afligitua egondu da iru orduz gurutcetic chinchillica zure sabeleco frutua, Jesus». Santa Maria, etc.

\section{Stabat autem et ut supra Josseph autem et ut supra}

4. Paratcen ditugu gaur gure beguiac zugan, ama desamparatua, eta consideratcen ditugula zure soledadearen angustiac, acompañatcen zaitugu zure $<4$ r $>$ suspiro eta negar tiernoetan. Eta onetaraco diguzu Jeremias prophetaren agoz esaten: $\hat{o}$ vos omnes, qui transitis per viam, atendite et videte si est dolor sicut dolor meus. ${ }^{16}$ Mortalac, mundutic eternidadera caminatcen duzutenac, considera zazute atencioarequin eta beguira ote den doloreric nere doloreari iguala daquicoanic, tristezaric nere tristezari iguala daquicoanic ta soledaderic nere soledadeari iguala daquicoanic. Eta arrazoi justoarequin quexatcen da ama divina ori, cergatic duen bezala Bernardo dulceac ${ }^{17}$ advertitcen, cen Jesus Mariarenzat aita, esposoa eta semea, eta orain guelditcen da Maria aitaric bague emezurza, esposoric bague alargun ta semeric bague desamparatua. Cer eguin al dezaque gucia galcen duenac? Baldin Mariari falta bazaio alivioa, socorrua, consueloa, norgana acudituco du billatcera faltatu ezquero bere aita, bere esposoa eta bere semea, guelditcen dela emezurza, alargun ta desamparatua? Tu mihi Pater, tu mibi sponsus, tu mibi filius, tu mihi omnia eras. Nunc orbor Patre, viduor sponso, desolor filio, omnia perdo. ${ }^{18}$ Eta iru soledade oien rigoreac izanen dira gaur nere asumptoco iru puntu brebeac.

\section{Tu mihi Pater...nunc orbor Patre}

5. «O, Jaincoaren seme eguiazcoa!», du itceguiten ama santissimac, «O, Jaincoaren seme eguiazcoa! $\mathrm{Zu}$ ciñan nere aita eta orain guelditcen naiz aitaric bague emezurza. Esadazu, Jauna, etciñan zu nere aita? Engendratu ninduzun ezquero Jainco divinoac bezala, etcenituen nerequin eguiten aita amorosoaren oficioac? Baldin aitaren oficioa bada humea alimentatcea, ez ninduzun zuc zure providencia divinoarequin ni

16 ô vos... dolor meus: "Zuek, bidean zoaztenok, begira eta ikus: ba ote nirea bezainbateko oinazerik?» (Nk 1, 12). Itun Zaharreko Negar Kantetako lehenengoaren pasartea.

17 Bernardo dulceac: Ziurrenik Bernardo Clairvaux-koaz (1090-1153) ari da. Melifluo doktore ('ahoeztia') ezizenez ezagutzen zen bere sermoietan zerabilen leuntasun eta gozotasunagatik.

18 Tu... omnia perdo: "Zu zinen nire aita, nire senarra, nire semea, zu zinen guztia niretzat. Orain aitarik gabe nago, senarrik gabe alargundu naiz, semeak utzi nau, galdu dut guztia». Aipu hau, hain zuzen ere, Bernardo Clairvauxkoaren sermoietako batetik hartua da, De passione Christi, et dororibus, et planctibus Matris ejus da sermoia (ik Binetti eta lan honetan $\$ 1$. atala). Latinezko aipuaren itzulpena gurea da. 
sustentatcen? Baldin aitaren oficioa bada humeari declaratcea secretoric ocultoenac, etcenitidan zuc niri revelatcen misterioric soberanoenac? Ez ninzan ni zure alaba bacarra, zurequin batean gauza guciac componcen nituena? Nigan ongui descubritcen cen zure consejua, zure clemencia, gurasoarequin humearequico amorioa. Eta orain ecustearequin zu gurutce orretan defuntu, guelditcen naiz aitaric bague emezurza. Alaba $<4 \mathrm{v}>$ bacarra eta desamparatua consideratcen naiz. O, soledadearen rigore cruel samiña!»

6. «Zure Magestadea idero cenean desiertoan bacarric, desamparaturic, Aita Eternoac bidaldu cerazquizun aingueruac lagunceco, asistitceco, consolatceco. Eta gueroena bart arratsean Getsemanico baratzaco ${ }^{19}$ agonia congojosoan aguertu citzaitzun aingueru bat confortatcera, ecusiric zu ain congojatua icercen ciñala odolez. Eta, baldin nai izandu bacenu idequi agoa, bidalduco cituen Aita Eternoac zure alivio ta consueloraco desamparo triste artan amabi exercitu aingueru baño gueiago. Bada, nere Aita, nola falta zait niri alivio ta consuelo gucia bici naizalaric ain desamparatua ta bacarra? Da posible zure entraña amorosoac nitaz ez compadecitcea? Da posible ez iderotcea ni confortatceco alivioric chiquiena desamparo bat ain cruelean? Ylluntasunac bai, amargurac bai, samintasunac bai ni afligitceco eta gueiago atormentatceco. Quexatu ciñan gurutceco agonian Aita Eternoaren desamparoaz. Bada, nola nic, nere aita, ez dut quexatu bear zure desamparoaz, uzten nazula bicitzarequin ain desamparatua padecitceco?»

7. "Quexatu cenean Eliseo ${ }^{20}$ bere maisu ta aita Eliasen ${ }^{21}$ ausenciaz, ecusiric Eliseoren negar ta malco tiernoac, etcen compadecitu Elias? Etcion utci soñean zacarren capa servi ciezaion aliviotzat bere aitaren ausencian, ematen cerazquiola artan fuerzac eta espiritua sufritceco animoarequin ausenciaren desamparoa? Bada, nere aita amorosoa, cer prenda, cer alaja uzten didazu zure ausencian nere alivioraco desamparo bat ain cruelean? Cer utci bear didazu, baldin nere escuz eguin nizun capa edo tunica guelditu bada borreroen escuetan faltaceco niri alivioac eta augmentatceco tormentuac? Nere Jaincoa, amatcen zaitut nic zu Eliseoc Elias ${ }^{22}$ baño guchiago? Ez, baicic guztiz gueiago, nere aita. Bada, nola izandu cen Eliseo Eliasgandic privilegiatua eta falta da neretzat privilegio ori? $<5 r>$ Veguira zazu, Jauna, ni naiz zure alaba bacarra. Nola izandu dituzu entrańac uzteco ni desamparaturic emezurza?»

8. «Baña ya, ezagutcen dut, nere aita, zu iderotcen zaran bezala zure aita eternoagandic desamparatua nic experimentatceco desamparo triste orren rigorea, nai duzula ni egotea desamparatua zugandic, baitzara nere aita. Milla gustoz, Jauna, cumpli bedi zure vorondate santua nere bicitzac padecitcean soledade samiñ au. Baña, nere Jaincoa, esperanzarequin guelditcen naiz consolatuco nazula onenbeste soledaderen ondorean. Bada, zaralaric zu neretzat ain aita, baldin emezurza gucienzat bazara aita,

19 Getsemanico baratza: Bertan biltzen omen ziren Jesus eta apostoluak maiz, eta Itun Berriaren arabera (Mt 29, 36; Mk 14, 32), Jesusek bertan egin zuen Judas Iskariotek saldu eta atxilotua izan aurreko azken otoitza. Lukas ebanjelariak (Lk 22, 39) Oliamendi deitzen dio, «mons Olivarum».

20 Eliseo: profeta hebrearra (K.a. 850-800). Elias profetaren oinordekotzat hartua.

21 Elias: K.a. IX. mendearen hasieran aritu zen profeta hebrearra.

22 Eliseoc Elias: Itun Zaharreko Erregeak liburuko (1 Erg 19, 19-21) pasarteari egiten dio erreferentzia. Bertan esaten denez, Jainkoak Elias Damaskora bidali zuen eta Eliseo oinordekotzat hartzeko agindu zion. Eliasek hala egin zuen, Eliseo goldaketan zela, Elias ondotik pasatu zitzaion, eta bere soingainekoa bota zion. 
duen bezala propheta santuac ${ }^{23}$ esaten, arrazoi gueiagorequin izanen zara neretzat aita especiala, cergatic naizan zure alaba bacarra, alabaric favorecituena, afligituena, desconsolatuena eta desamparatuena. Baña, nere Jaincoa, logratuagatic nic alabaren consueloac, tormentu au pasatcen denean, zarala zu nere alivioa ta consuelo gucia, cer eguin al dezaquet, baldin zu bazara nere aita bezala, tu mihi pater, nunc orbor $\mathrm{Pa}$ tre, esposoa ere? Au da nere soledadearen bigarren rigorea, ez galcea zu solo aita bezala, baita ere esposoa bezala.»

\section{Tu mihi sponsus, nunc viduor sponso.}

9. «O, Jaincoaren seme eguiazcoa! $\mathrm{Zu}$ ciñan nere esposoa, eta orain guelditcen naiz esposoric bague alargun. Zu ciñan, Jauna, neretzat esposoa, gucia amorioa, gucia consueloa, gucia felicidadea. Nic nai nizun zuri esposa agradecituac bezala, eta zuc esposo leialac bezala billatcen ninduzun, regalatcen ninduzun zure amorioaren ternura dulceaquin. Eta orain ecustearequin zu gurutce orretan defuntu, guelditcen naiz esposoric bague alargun. $\mathrm{O}$, dolore andia, martirio cruela, soledadearen rigore samina!»

$<5 v>10$. «Atera cen atcenecoa bart arratsean cenaculotic ${ }^{24}$ nere esposo dulce maite au, eta caminatu zuen Getsemaniaco baratzan barrena Calvarioco mendira ardi mansoac eta bildots inocenteac bezala. Eta orain, ay, nere desamparatua!, registratcen dute nere beguiac illa eriotz afrentosa batequin. Cer eguin al dezaquet nic nere esposoa bague eta ain desamparatua? Cer eguin al dezaquet nic, baldin nere bihotza badagoquit esaten eztudala aditu bear gueiago nere esposoaren voza dulcea? Baldin beti, nere Jaincoa, izandu baciñan neretzat ain esposo dulcea, nola zara orain ni atormentatceco ain esposo cruela? Nola, uzten nazula bicitzarequin ain congojatua, il zara cere vorondatez gurutce cruel orretan? Nola ematen didazu martirio bat ain cruela, uzten nazula esposoric bague alargun? Nola etzara compadecitcen, escusatceco eriotza, ecusteaz ni guelditcen naizala ain desamparatua eta desamparo triste onengatic nere bicitza gucian negarrez urtu bear dudala?»

11. «Nere esposo dulce maitea, iderotcen ciñanean becatarien billa, fatigaturic, cansaturic, desamparaturic, bacarric goiceco inza eta arratseco euria beste alivio ta abrigoric bague, deitcen zanidanean atea idequi niezazula ta nere compañian admiti, ez nizun compadecituric atea idequi, nere compañian admititu eta zu alimentatceco nere escuz sustento guisatu? Bada, nere esposoa, baldin ni leneco esposa ura bera banaiz, nola zure esposaren deadarraz eta ay ${ }^{25}$ tristeaz, etzara compadecitcen? Nola uzten nazu alarguntasun samin onen arrats tristean? Yl nadin ni zurequin batean, nere esposoa, libratceco ain martirio crueletic. Baña, Jauna, den casoan zure vorondate santua ni onela guelditcea, cumpli bedi milla gustoz. Emen egonen naiz zurequin crucificaturic alargun desamparatua bezala, izan bague norc defendi nazaquean, norc alivia nazaquean, norc consola nazaquean, norc visita ta honra nazaquean. $<6 r>$ Bada

${ }^{23}$ Propheta santuac: Ziurrenik Dabid profetaz ari da. Itun Zaharreko salmoetako batean hala dio Dabidek: «Umezurtzen aita, alargunen defendatzaile da Jainkoa bere bizileku santutik» (Sal 68.6). Betebetean lotzen zaio sermoiaren gaiari.

24 cenaculo: Jesusek eta apostoluek azken afaria egin zuten lekua.

25 ay: ik. 11. oin-oharra. 
eztezaque, nere esposoa, niorc ere, niorc ere supli nic zugan gaur galdu dudana. Baña, ay, dolorea! Ezta nere martirioric ${ }^{26}$ cruelena guelditcea esposoric bague alargun, tu mihi sponsus, nunc viduor sponso, oraindic cruelagoa da guelditcea semeric bague desamparatua. Au da nere soledadearen irurgarren rigorea.»

\section{Tu mihi filius, nunc desolor filio.}

12. «O, Jaincoaren seme eguiazcoa! $\mathrm{Zu}$ ciñan nere semea eta orain guelditcen naiz semeric bague desamparatua. Cer eguin du ama onec ain tiernoqui amatcen zuen seme bacarra galceco? Asco ezpailiz bezala semeric bague desamparatua guelditcea, nai izandu duzu gueiago nere beguiz ecus zaitzadan ainbeste tormentu padecitcen eta afrenta andiarequin ilcen? Onenbat pena experimentatceco escogitu ninduzun zure amatzat? $\mathrm{O}$, dolorearen ezpata zorrotz cruela! $\mathrm{O}$, soledade desamparatuaren rigore samiña!»

13. Norc oraindic ecusi ditu dembora batean elcarrequin eguzquia eta yllargia illuncen? ${ }^{27} \mathrm{Ez}$ lizaque au naturalezaren ordena gucia mudatcea izanen? Eta, bada, baldin mundu onec acabatu bear duen artean ${ }^{28}$ ezpada onelaco novedaderic ceruco planeta eder orien artean ecusi bear, estalcen dela illuntasunaz eguzquia, vestitcen dela odolez yllarguia eta erorcen dirala lurrera yzarrac, nola gaur ecusten da eguzquia illundua, yzarrac eroriac eta yllarguia odoletan? «Da posible», du esaten ama divina orrec, "cergatic naizan Christoren, ${ }^{29}$ justiciaren, eguzqui divinoaren ama, eguzquiagandic claridade eta edertasuna arcen dudan yllarguia, eta nere bi beguiac bi izar bezala beti firmeac iduqui ditudan ceru gustoaren ${ }^{30}$ ama, da posible orain ecusi bear dela nere seme eguzqui divinoa eriotzarequin illundua, nere arpeguico cerua tristeturic bi beguiac bi izar bezala eroriac, eta ni, yllargui betea, nere semearen llaguen ta heriden odoletan gucia?»

$<6 v>14$. «Fingitu zutenean Jacoberen semea ${ }^{31}$ fiera batec despedazatu zuela Joseph semeric gazteena, emanagatic noticia au bere aita Jacoberi, valerosoari bezala, etcioten participatu bere amari etcezan pesadumbrez bicitza galdu. Eta nic, nere Jaincoa, ecusi ezquero despedazatcen Jerusalengo fieraric cruelenengandic, ez solo Jacobec bezala vestidura odoldua fiera borreroen escuetan, baicic, orrez gañera, ecusi bear dut nere seme dulce bacar maitea bere soñean ecarri duen gurutce afrentosa orretan, guelditcen naizala betico desamparatua espectaculo triste orri beguira? Eta, enfin, Jauna, guelditu bear dut bacarric, alivioric bague, consueloric bague, eztela nitaz compadeci daitequeanic? Bada, nere semea, etciñan zu onelaco desamparoaz que-

\footnotetext{
26 martirioric] esk. martirioc.

27 illuncen] eskuizkribuan irakurketa garbia da, baina, beharbada, illuncean behar luke, artikuluarekin.

28 artean] esk. artea.

29 Christoren] esk. Xtô, genitibo markarik gabe.

30 gustoaren] esk. gusto aren; irakurketa garbia bada ere, ez da erraza interpretatzen. Agian grafian hutsa egon daiteke eta justoaren uler liteke; dena den, $\langle\mathrm{g}>$ ongi irakurtzen da.

31 Jacoberen semea: Josef da Jakob eta Rakelen semea. Jakobek hamabi seme izan zituen, ez, haatik, guztiak Rakelekin, eta horietarik gazteenetarikoa zen Josef. Aitaren kuttunena zenez, gainerakoek inbidia zioten eta anaia gaztea hiltzea deliberatu zuten. Lehenik putzu batera botata hiltzea erabaki zuten, baina azkenean merkatari batzuei esklabutzat saldu zieten. Aitari Josefen tunika odoldua erakutsi zioten, piztia batek jan zuela esanez.
} 
xatu? Nola nic utci al dezaquet quexatceco, baldin iderotcen banaiz, nere entrañetaco seme dulce bacar maitea, galduricaco desamparo ta soledade tristean? Eta izan bear ote dute remedio bagueac nere negar tiernoac?» Bai, ama maitea, eta orrengatic Escritura Sagraduac contatcen dituen negar gucien artean, solo Ana Tobiasen amarenac $^{32}$ contatcen ditu remedio bagueac, cergatic galdu zuen semea. Baña nic comprehenditcen dut, señora, etcirala Anaren negarrac remedio bagueac cergatic galdu zuen semea, baicic cergatic ciran zure gaurco negar tiernoen representacioac. Badirudi, ama maitea, eztutela zure gaurco negarrac remedioric. Orrengatic, bada, du esaten ama divina orrec: «Nago eta egonen naiz beti negarretan urcen. Bada, izan bague asco guelditcea aitaric bague emezurza eta esposoric bague alargun, allegatu naiz guelditcera semeric bague desamparatua».

\section{Tu mibi filius, nunc desolor filio.}

15. «Cein ama izandu da edo izanen da tempora batean ainbeste galdu duenic edo gal dezaqueanic? Modu gucietan galdu dut, ta laster galduco dut, gorputzaren compañia ere. Cergatic, bereala etorrico dira eta emanen diote sepultura indecenteren bat, augmentatceco nere soledadearen rigoreac. Bada, atrevitu cena ill ezquero costaduco lanzada $<7 r>$ cruela ematera, prompto egonen da edozain maldade executatcera. $\mathrm{O}$, ez dezazula arren nai izan, nere Jaincoa! Zure providencia divinoari tocatcen zaio beldur naizan desgracia onen remedioa. Veguira zaiozute zure ama desamparatuaren suspiro ta negar tiernoai. Preveni zazu, Jauna, medioren bat gorputz defuntu orren ultrage ta crueldadeac estorbatceco. Yduritcen bazaitzu eztela piedaderic guizonen bihotcetan (baña bai izanen da), badituzu aingueru asco. Bidali tzatzu, Jauna, aingueruren batzuec dañu onen remedioraco.»

16. «Baña, ${ }^{33}$ ay, nere desamparatua! Badirudi eztela nere deseoa logratcen. Cerua itsia dago. Aita eternoac ez nau aditcen. Norgana acudi al dezaquet? Aingueruac, nere semea desiertoco desamparoan aliviatu zanutenac, ainguerua, nere semea Getsemaniaco baratzaco agonia congojosoan confortatu zanuena, asisti zadazute clemenciarequin necesidade andi onetan. Disponi zazu, nere Jaincoa, conforma dadin nere deseoa zure vorondate santuarequin.» Ea, catholicoac, iderotcen bada gure bihotcetan piedaderic, pretendi dezagun gure ama maite Mariarenzat alivio ta consuelo chiqui au. Esan dezagun princesa divina orrequin batean: «O, arbola santua! $\mathrm{O}$, gurutce santissimoa cerua baño gorago alchatua zaudena, flecte ramor arbor alta, tensa laxa viscera! ${ }^{34}$ Bera tcitzu adar oriec, inclina tcitzu lurreronz beso oriec, or, or ideroco duzu ceru obe bat, or daucazu Maria edertasunen ta negar tiernoen ceru gustosoa. Dobla zazu beitironz zure besoen rigorea Mariaren ternura dulceetara. Ytzuli zazu, arbola santua, itzuli zazu pechu amante aietara bere sabeleco fruitu bedeicatua». Baña, ay, dolorea! Delaric gurutcea beste gucienzat ain dulcea, gaur Mariarenzat dago ain cruela, non eztituen lurrera inclinatu nai bere besoac, alic eta guizonen bihotzac

\footnotetext{
32 Ana Tobiasen amarenac: Ana Tobiten emaztea eta Tobiasen ama, Itun Zaharreko Tobiten liburuaren arabera $(\mathrm{Tb} 2,1)$.

33 Baña] esk. Bana.

34 flecte... laxa viscera: San Tomas Akinokoaren Pange lingua-tik hartua, Ostiral Santuan abesten bide zen.
} 
apiadaturic fuerzaz inclina ditzaten artean. ${ }^{35}$ Apiada beitez Joseph ta Nicodemus, ${ }^{36}$ cein lograturic Pilatosen licencia erausteco gurutcetic gorputz santu ori, prevenitcen ari dira instrumentuz Calvariora caminatceco.

17. Ea, princesa soberana, animo, valore! Ya ceruac, compadecituric zure lastimaz eta lastimaturic zure negar $\langle 7 \mathrm{v}\rangle$ tiernoaz, disponitcen du norc honra dezaquean zure seme defuntua, eta norc alivia ditzaquean zure penac. Ytzuli itzatzu, itzuli itzatzu zure begui misericordiazco dulce oriec ciudadeco ${ }^{37}$ portaleronz. Orra, orra non eldu diran Joseph ta Nicodemus zure semearen discipuloac zure pena andiac aliviatcera.

18. Ya assitcen da gure Jaincoa triumphatcen ta reinatcen gurutceco solio ta tronutic. Bada, len beldurrarequin gab illuna billatcen zutenac, hic venit ad Jesum noc$t e,{ }^{38}$ orain egun arguiz declaratcen dira Christoren discipulotzat, adoratcen dutela beren maisutzat guizon crucificatu bat. Adoraturic Christo, belauricatcen dira ceruco erreguiñaren ońetan. Eztute, señora, zuri licencia escatceco animo ta valoreric. Bada, ecusiric zure arpeguico ternura solo, cuidatcen dute, len baño len, zuri gusto ematea. Eta, izanic ere costumbrea ajusticiatuen gorputzac ${ }^{39}$ borreroac eraustecoa, ceruco decretoz, crucificatu divino ori eraustera ez borreroac, bai principeac, ${ }^{40}$ ez cruelac, bai piadosoac igotcen dira gaur escalera orietan. Ygo zaitezte, principe nobleac, igo zaitezte coroatcera defuntu divino ori zuen besoen fineza piadosoaquin. Zarate serafin ${ }^{41}$ gurutceco solioan Jaincoa honratcen duzutenac. Zarate bi kerubin ${ }^{42}$ zuen fedearen egoaquin jaun soberano ori besarcatcen duzutenac.

19. Deitcen diotelaric Eliza ama santac gurutceari eta ilceai «dulceac», dulce lignum, dulces clavos, deitcen dio lanzari "cruela», mucro diro lanceae, ${ }^{43}$ cergatic, baldin crueldade andia bada heritcea gorputz bicia, ezta chiquiago heritcea bihotz illa. Baña, baldin consideratcen badugu jaun soberano orren bihotceco dulzura, ideroco dugu gurutcea ta ilceac baño dulceagoa dela guretzat lanza, cergatic, baldin gurutceac eta ilceac heritu bazuten Jesusen gorputza, oñac eta escuac, lanzac heritu zuen bihotza, uzten cigula idequiric ceruraco videa eta atea. Baña, Jauna, dela dulcea edo dela cruela, nori entregatu bear zaio lanza? Ori ta beste guztiac du eranzuten jaun soberano orrec: «Entrega bequitza nere ama maiteari, nere alaja pobreen heredera baca-

35 artean] esk. artea.

36 Joseph eta Nicodemus: Joan ebanjelariaren arabera (Jn 19, 38), Jose Arimateakoak Jesusen gorpua hilobira eramateko baimena eskatu zion Pilatosi, eta honek eman. Nikodemo azaldu zen ondoren mirra eta aloe nahasturekin. Bien artean gorpua hartu eta oihal zerrendaz lotu zuten juduen ohiturei jarraituz.

37 ciudadeco] esk. cuidadeco.

38 hic... ad Jesum nocte: "Gauez Jesusengana etorri [zen]» (Jn 3, 2). Joan ebanjelariaren arabera, Nikodemo gauez joan zen Jesus bisitatzera eta elkarrizketa sakona izan zuten biek.

39 gorputzac] esk. gorputzat.

40 principeac: Nikodemo fariseoa eta juduen buruetako bat zen (Jn 3, 1), eta Jose Arimatekoa, dirudienez, Biltzarre Nagusiko kidea zen (Mk 15, 43); ez ziren, beraz, maila apalekoak, goi-mailakoak baizik.

41 serafin: Kristautasunaren arabera, zeruan den aingeru mota da.

42 kerubin: Kristautasunaren arabera, Jainkoaren gloria babesten duen aingeru mota bat da.

43 ...mucro diro lanceae: Elizak «dulces» adjektiboa eman zion Jesusen gorpua zetzan gurutzeari eta bertan sostengatzen zuten iltzeei. Aldiz, soldaduak Jesusen bihotza zulatzeko erabilitako lantzari "punta zorrotzdun lantza krudela» deitu zion. San Tomas Akinokoaren Pange lingua-n agertzen dira esaldi hauek, eta Ostiral Santuan abesten bide zen. 
rrari bezala. Bada, leitu du nere bihotz idequico testamentan nori derechoz tocatcen zaizcan». Recebi zazu, $<8$ r $>$ bada, señora, recebi zazu zure bihotz tiernoa atravesatu zuen lanza ori, eta guero aingueru baten escutic entrega zaiozute nere auditorioco bihotz gogorrai. Entrega zaiozute gaitza gaitzarequin pagatcen daquiten pozoituai, orretan ecus dezaten zure bihotceco berotasuna. Nai duzute, catholicoac, aditu norańo allegatcen cen Maria Santissimaren venganza etsaien contra? Du escribitcen bere discipula eta alaba Maria Jesus de Agredac ${ }^{44}$ ecusi zuenean Longinosec atravesatu ciola bihotzaren erditic lanza, atcenduric bere penaz eta compadecituric Longinosez esan ciola: «Ceruco Jainco guztiz poderosoac beguira diezazula misericordiazco beguiaquin nere animari gaur eman diozun penagatic». Onaraño allegatu cen señora orren colera ta venganza, edo obequi esan dezadan, paciencia, humildadea edo mansedumbrea, ofendituac izaten garan gucien exemplo ta doctrinaraco. Eta zuec, catholicoac, aditu orduco zuenzat injuria bat, ecusi orduco demonstracio edo agravio bat, bereala bihotzac pozoituric odioa, venganza, ecin ecusia, gaitz deseatcea, maldicioa, murmuracioa.

20. Jacobec ecusi zuen escalera ${ }^{45}$ eta, artan igotcen ta jaisten aingueruac, ascendentes et descendentes, izandu cen gaurco gurutce orren escaleren profecia. Eraustera cerutic Jaincoa igotcen ciran aingueruac eta eraustera gurutcetic Christo igo dira escalera orietan bi guizon aingueru. Baña cein admiratuac? Cein espantatuac eta aturdituac? Cer diozute guizon piadosoac? Beguira zaiozute expectaculo triste orri. Cer iduritcen zaitzute tormentu cruel orietaz? Baña cer diozute zuec, aingueruac eta serafinac? Ezagutcen duzute norena den reverenciarequin adoratcen zauten gorputz ori? Ecetz dute eranzuten, quis est iste, qui venit de Edon tinctis vestibus? 46 "Nor da?», diote admiraturic elcarri aingueruac galdatcen, «nor da munduco batallatic gucia heritua, lastimatua, odoldua eldu den au?» Guc, becatariac, eranzun dezaquegu: «Guizon divino ori da gure culpac bicitza quendu diotena. Ez, arren, aingueru santuac, gure contra asserretu. Asqui da, bere ama presente dagoenac guri barcatcea. Eta zuec, ministro piadosoac, esca tcitzute pañu edo banda oriec, ceñec sustentatu bear duten Jainco infinito baten pisu andia. Lotu zazute pechu amante eritu $\langle 8 \mathrm{v}\rangle$ ori. Estal zazute gu or sarceco lanza gogorrac idequi dion bihotzeco ${ }^{47}$ ate ori. Dichosoac zuec, exercitatcen zautenac, temploco kerubinen oficioa, ${ }^{48}$ bada zuen afectoen egoaquin, kerubinac bezala, tapatcen duzute propiciatorio santu orren lotsa ta afrenta».

21. Ain aborrecituac zauzquien jaun soberano orrec mundu onetaco honrac, non, paraturic buruaren gañean erregueren titulotzat rotulo escribitu «Jesus Nazarenoa Juduen Erreguea» esaten duen ori, ilceco temporan retiratu zuen bere burua ama zagoen escuñeco aldera, esaten baitzuen bezala: «Eztut nic nai beste reinuric mun-

${ }^{44}$ Maria Jesus de Agreda: xvII. mendeko abadesa, moja eta idazle mistiko espainiarra, frantziskotarra. Hainbat obra idatzi zituen, besteak beste, Ama Birginaren bizitza. Bertan kontatzen da sermoian aipatzen den gertakaria.

45 escalera: Testamentu Zaharraren arabera (Has 28, 12), Jakobek amestu zuen eskailera bat ikusten zuela beheko ertza lurrean eta goikoa zeruan zituena; bertan Jainkoaren aingeruak zebiltzan gora eta behera.

46 quis... tinctis vestibus: «Nor da Botzratik, Edomgo hiriburutik, soineko gorriz tindaturik datorren hori, jantzi dotorez, indar-kemenez datorren hori?» (Isaias 63, 1).

47 bihotzeco] esk. biohtzeeco.

48 kerubinen oficioa: hain zuzen ere, kerubinen lana tenplua edo zerua zaintzea da. 
duan, baicic truncu cruel onec eman didana. Gueldi bedi nere reinu gucia nere ama maitearenzat». Quen zaiozute, guizon piadosoac, erregueren titulo ori eta entrega bequio ama maite o[r]ri guarda dezan beretzat. Bada, baldin erregue Asueroc ${ }^{49}$ coroatu baño len ofrecitu bacion Esterri bere reinuaren erdia, Christo ceruco ta lurreco erregue eguiazcoac ez bere reinuaren erdia, baicic piedadearen ta misericordiaren reinu gucia ofrecitcen dio gurutceco tronutic Esther divina orri. Recebi zazu, ceruco ta lurreco erreguińa, recebi zazu, misericordiaren ama, recebi zazu titulo ori, eta coroa bedi zure piedadea ceruco ta lurreco imperio guciarequin. Goarda zazu, señora, ceretzat depositatcen duzula aingueru baten escuetan erregueren insignia ori, eta leitu zazu noicean bein espacioz, acordatcen zarala egun dichoso artaz, ceñetan ${ }^{50}$ iru Erregue Magoac adoratu zuten zure semea Belengo portalean erregue gucien erreguetzat. Ha, cein honra anditaco eguna ura! Eta, ha, cein afrenta anditacoa au! Baña, o, erregue andia! Zuc solo jaquindu duzu ongui governatcen ematen duzula cere vasalloacgatic bicitza.

22. Bi coroa cituen artificio andiarequin antiguaco oguien proposicioco maiac. Deitcen citzaion batari coroa eta besteari aureola. Lendabicico coroa cen trabajuena, eta premioena bigarrena. Bada, baldin trabajuen coroari justiciaz zor bazaio premioen $<9$ r $>$ coroa, emaiozute, Jauna, guizon piadoso oriei licencia quenceco zure burutic aranzazco trabajuen coroa ori. Bada, arrazoi justoa da, ya hainbeste trabajuren ondorean, noizbait-noizbait ${ }^{51}$ resplandeci dezan premioen coroac. Becatari ingratuac, despreciaturic zure copetaco icerdi amanteac, ceñequin izandu cen ain favorecitua, corresponditu bearrean agradecituric lore dulceac, pagatu derazquitzu iruroguei ta amabi aranzazco lanzada afrenta andicoac, baña baldin becatari gogorrac itzulcen baditu agradecimentuen loretzat aranzac, badaquit nic Maria santissimac convertituco dituela aranza oriec lore dulce eta arrosetan. Recebi zazu, ${ }^{52}$ señora, recebi zazu alaja ori, ez zure bihotza orrequin puscatceco, asqui puscatua daucazu, eta aingueru baten escutic entrega zaiozute soberbioai para dezaten beren buruetan. Zure buruac eztu aranza bearric, bada zara excelenciaz guztiz humilla. Gure soberbiac, gure vanidadeac, gure andi naiac bear ditu humillatceco aranzac. Soberbioac, coroa tcitzute zuen buruac aranza aiequin humillatceco, esperanzarequin ama divina orrec convertituco dituela lore dulce ta arrosetan.

23. Baña, ay, Virgina dolorez betea! Ya ilceac sarcen zure biotza partitu zuten malluen golpeac berriro deadar eguiten dute zure bihotz tiernoan. Ea, guizon piadosoac, atera zazute lenbicicoric escuńeco escuco ilce ori, gueldi dadin misericordia libraturic prisio bague. Tientoarequin, arren, poliqui, egonagatic defuntu, guztiz bicia dago señora divina orren bihotz tiernoan. Jatsi bedi orain gurutcearen escuńeco besotic Jaincoaren misericordiaren besoa. Or dago, catholicoac, or guganonz inclinatcen den escu orretan misericordiaren tronua eta cerura bear dutenen

\footnotetext{
49 Asuero: Persiako erregea (K.a. 486-465). Testamentu Zaharreko Esterren liburuan agertzen da. Ester bera hartu zuen emaztetzat.

50 ceñetan] esk. ceñeten.

51 noizbait-noizbait: eskuizkribuan bi aldiz agertzen da noiz bait noizbait; ez dirudi, beraz, errata denik. Itxuraz, «behingoz» esanahia du, Lazarragaren noxbait-noxbait adibideak (Bilbao et alii 2010) eta beranduago Agirre Asteasukoarenak bezala (ik. OEH, s.v. noizbait).

52 Recebi zazu] esk. Recebiza. Hutsa dirudi testuingurua eta jarraian duen recebizazu kontuan izanda.
} 
asentua. O, ilcea, clemenciaren atearen guilza izandu ciñana! O, ilcea, becatuagatic guretzat itsia zagoen ceruco atea idequi zanuena! Eta, bada izandu ciñan misericordiaren atearen guilza, servi zaiozu Maria santissimari, baita ceruco atea eta misericordiaren ama. Recebi zazu, señora, recebi zazu ilce ori eta, adoraturic aingueru baten escutic, entrega zaiozute misericordiaz usatcen eztaquitenai, $\langle 9 \mathrm{v}\rangle$ entrega zaiozute codiciosoai, berenaz contentatu bague, besterena nai luqueten embidiosoai, icas dezaten codiciaren escua crucificatcen misericordian ta clemencian convertitceco.

24. Ea, guizon piadosoac, atera zazute ezquerreco escuco ilce ori, baña ez, ez atera justiciaren escutic, cergatic, baldin jaisten bada rigorearen besoa gurutcetic, emanen digu gure maldadeac mereci duten castigua. Catholicoac, etzarate reparatcen atera dela ya ilce ura? Eztituzute sentitu zuen bihotcetan malluen golpeac? Guztiac izandu dira justiciaren amenacen avisoac. Baña cer da nere beguiac registratcen dutena? Ay, gure galduac! Justiciaren rigore gucia dator lurrera. Becatoriac, izu zaitezte, icara zaitezte. Eroriaz dijoa castiguen besoa. Ay, desdichadua ura ceñen gañera erorcen den. Baña anima beitez, catholicoac, gure bihotzac, cergatic, gurutcean josi ezquero, ain piadosoa dago ezquerreco escua nola escuñecoa. Ylcearen zuloarequin idequi cen gucioc ceruan sarceco atea. Recebi zazu, bada, señora, recebi zazu justiciaren escuco ilce ori, eta adoraturic entrega zaiozute aingueru baten escutic justiciaco ministroai, icas dezaten zuri ainbeste congoja ematen dizuten amancebamentuac, desonestidadeac eta escandaloac castigatcen. Entrega zaiozute humeen cargua duten gurasoai castiguaren rigorearequin ceruraco cria ditzaten.

25. Ya arrazoia da noizbait-noizbait ${ }^{53}$ atera dadin gure salvacioagatic ainbeste pauso amoroso eman cituzten oń oriec preso dauzquien ilcea. Asqui da prisioric, nere Jaincoa. Bada, ya zure ońen esclavitudearequin gaude gucioc redemituac. Ea, ministro piadosoac, atera zazute ilce ori, tientoarequin arren, poliqui, barach. Ay! Golpe oriequin transpasatcen duzute ama maitearen bihotza, cergatic da preciso acorda dadin egun goicean gure ingratitudeac oin divino orietan eman dituen mallu golpe cruelaz. Diluvioco temporan etzuen usoac idero idorric ońac non paratu, baña egatu cen. Yderotcen cen Noeren arca timoric ${ }^{54}$ edo ilceric bague, eta orrengatic egatcen cen ta itzulcen nai zuen bezala. Baña zu, ama dolorez betea, ecin cindezquean egatu ta apartatu gurutce orretatic, cergatic zure semearen $<10 \mathrm{r}>$ ońetaco ilceac loturic zauzquien zure bihotzaren egoac. Recebi zazu, bada, uso churia, ama afligitua, recebi zazu zure semearen ońetaco ilce ori eta, adoraturic ainguerucho baten escutic, entrega zaiozute pauso macurretan bici diradenai, entrega zaiozute becatuco ocasioan dabilzan desonesto torpe amancebatuai, infernuraco ematen dituzten pauso macurrac zucen ditzaten ceruraco.

26. Ya badirudi truncu cruel orrec nai duela beregandic despeditu ta libratu preso divino ori eta itzuli erdi zuen amaren besoetara. Ay, princesa soberana, nola-

53 noizbait-noizbait: ik. 51. oin-oharra.

54 timoric] eskuizkribuan argi jartzen du timoric, baina timor ez dakigu zer den. Beharbada, hutsa izan liteke, eta timoiric edo timonic zuzendu beharko litzateke. Euskal tradizio idatzian timoi lekukotzen da Larramendiz geroztik, baina Nafarroan ez litzateke arraroa timon erabiltzea. xviI. menderako ladronaq, millonac eta bofeton lekukotzen dira, baina ez dugu timon inon aurkitu. Goizuetako $1897 \mathrm{ko}$ ordenantzetan cuestion eta mojonac lekukotzen dira. 
coa entregatu zanigun zure entrañetaco fruitu bedeicatu ori! Eta, ay, nolacoa itzulcen dizugun, becatari ingratoac! Ea, señora, animo, valore! Prepara tcitzu besoac seme defuntua recebitceco, prepara tcitzu beguiac malcoz odolac garvitceco, ezpañac heridetan musu eguiteco eta zure bihotz afligitua gure contra ez asserretceco. Baña recebitu baño, beguira zaiozu atencioarequin ote den zure semea. Ezagutcen duzu arpeguico semblante ori? Herida espantoso oriec? Yruroguei ta amabi aranzaz zulaturicaco buru ori? Ystu ciquiñac illunduricaco begui oriec? Bofetadaz odolduricaco matrall oriec? Bost milla ta gueiago azotez urraturicaco espalda oriec? Ylcez transpasaturicaco escu ta oń oriec? Lanzaz atravesaturicaco bihotz ori oraindic odol bicia dariola? Ori ote da, señora, zure semea? Ori bederetci illabetez zure sabelean iduquitu zanuena? Ori ote da zuc Belengo portaleco cueban erdi zanuen aur eder ura? Eztezaquezu ezagutu orain dituen señale orietan, baña ezagutuco duzu paciencian, ceñequin gure amorioan abrasaturic ainbeste sufritu duen. Ezagutuco duzu mansedumbrean, ceñequin oraiñ ere ${ }^{55}$ orrela paratu dugun ingratoai barcatu nai digun bihotcetic arrepentitu nai badugu. Onetan ezagutuco duzu dela ori zure semea.

27. ${ }^{56}$ Recebi zazu, bada, señora, zure beso amanteetan, eta ez seculan berriz becatariai entregatu. Guarda zazu alaja divina ori ceretzat, baduzu experiencia gure ingratitudeac cer eguin al dezaquean. Ya guizon piadosoac ematen dizute licencia eramateco defuntu ori amaren besoetatic catabura. Da posible, ama desamparatua, duzula valore $\langle 10 \mathrm{v}\rangle$ soltatceco Jesus zure beso amanteetatic? Baiez du eranzuten ceruco erreguiñac, nai diotela berriz becatariai berriro entregatu. Ama maitea, entregatu g[ur]ii? ${ }^{57}$ Entregatu berriz gure ingratitude cruelari? Baiez du eranzuten, nai duela ecus dezaten becatariac nolacoa paratu duten beren culpaquin. Ea, guizon piadosoac, eracutsi zaiozute nere auditorioari arpegui soberano ori. Catholicoac, cer iduritcen zaitzute? Baña, ay, nerea, ay! Ni naiz, Jauna, ni nere becatuaquin bicitza quendu dizudana. Aparta zazu nigandic zure arpeguia, averte faciem tuam a peccatis meis, ${ }^{58}$ eta eracutsi zaguzu gucioi gure remedioraco zure gloria. Baña cer gloria? Eracutsi ciona Moysesec bere espaldetan, posteriora mea videbis. ${ }^{59}$

28. Eta ori da, Jauna, gloria? Ori da gure gloria? Nola eztira gure bihotzac penaz puscatcen, ecusiric gu infernutic libratceagatic artu dituela jaun soberano orrec ${ }^{60}$ bere espaldetan gure becatuen carga guciac? Ay, becataria! An daucazu zure gloria. Ara non dagoen espalda aietan zure gloria, baldin zure correspondencia ingratoarequin ezpaduzu llaga lastimoso aietaco odol precioso malogratcen. Baña, ezpazara gaur zure becatuaz osoro arrepentitcen ta emendatcen, au izanen da zure condenacioco eguna. O, cerua! Cer izanen lizaque gutaz, baldin Maria santissima ezpalago

55 oraiñ ere] esk. oraiñ ere oraiñ ere; duplografia ziurrenik.

56 27] Eskuizkribuaren faksimilean ez da ongi ikusten 2 zenbakia.

57 guri] Ez da argi ikusten idatzita dagoena, baina $g$-z hasten dela dirudi, eta -iz amaitu

58 ...peccatis meis: Misesere mei izenez ezagutzen den salmoko pasartea (Sal 51). Salmo honek bekatuaren barkamena eta bihotz berria eskatzen ditu. "Aldendu begiak nire bekatutik».

59 posteriora mea videbis: Itun Zaharreko Irteerako pasarte bat. Jaunak Moisesi esan bide zion: "Hona hemen leku bat nire ondoan; zaude zutik harkaitz gainean. Nire aintza igarotzean, harkaitzuloan sartuko zaitut eta nire eskuz estaliko, ni igaro arte. Gero, eskua kenduko dut, eta bizkarraldea ikusi ahal izango didazu; baina ene aurpegia ez daiteke ikus» (Ir 33, 23).

60 orrec] esk. orren. 
gu favorecitceco ain empeñatua? Ya, Jauna, ezta valoreric ecusteco ainbeste llaga espalda orietan. Itzuli zaguzu zure arpegui soberanoa, esca diezazugun gure becatuen barcacioa.

29. Ay, becatariac eta gure galduac! Badirudi jaun soberano orrec ${ }^{61}$ gure ingratitudeen castigutzat desamparatcen gaituela. Aita amorosoa, gaurdanic ucatcen diguzu zure arpegui soberanoa? Ha, eta cein arrazoi andia daucazun apartatceco zure begui ederrac gure becatu itsusietatic! Ama maitea, iderotcen zaran casoan gu favorecitceco ain empeñatua, izan zaitez, arren, bitarteco. Baña, ay, becatariac! Penatua daucatela, dit eranzuten, pueblo ingrato onetaco becatu itsusiac $<11 \mathrm{r}>$. Beguira dezadala, dit aguincen, zuen animetara, gucion bihotcetara. Bai, ama maitea, ecusten dut onaco guizon vengativo escandaloso au, onaco emacume desonesta torpe au, araco mutill desobediente bere gurasoen martyrio ura, araco nescacha becatuco videan, peligroan ta ocasioan gaizqui confesatcen dela bici den ura. Cer diozu, ama maitea? Cer iduri zaitzu ainbeste ingratitudez? Ay, guizon escandaloso desordenatu Jaincoaren etsaia! Ay, emacume desonesta, torpe, ama maitearen etsaia! Zoazte, zoazte zuen venganza, escandalo, gula ta vicio ciquiñetara. Or, or egonen da vitartean jaun soberano ori isurcen zuecgatic bere odol gucia. Zoazte, zoazte zuen desonestidade, torpeza ta atseguin arce labur liquitsetara. Or, or egonen da vitartean ama maite ori zuecgatic negarretan urcen dela. Becatari ${ }^{62}$ tristeac, guelditu bear ote duzute gaurdanic betico desamparatuac. Orañ ere esperanza nuque entraña piadoso aietan, baldin zuec arrepentitcen bacinate. Esadazute: arrepentitcen zarate? Bihotcetic osoro bai? Ayta amorosoa, beguira zazu cariñoarequin gure gucion bihotz arrepentituetara, itzuli zaguzu zure arpegui soberano ori. O, Jaincoaren piedadearen andia! Ea christabac, ea becatariac, itceguin bezate bihotzac. Nere Jesu Christo, etc.

30. Orobat izandu cen ausentatcea semea amaren besoetatic, baña ez bihotz dolorez bete artatic, nola assitcea disponitcen entierroa solemnidade andiarequin, acceptatcen cituela Aita Eternoac sepulturaco aldare gańean bere seme bacarraren justiciaco sacrificioa. Mariaren dolore tiernoen vorondatezco ofrenda, eta beren pechuac erioza bat ain lastimosoaren penen golpez heritcen cituztenen sacrificioa. Becatari Christo ilzalleac, ocasio ona duzute au sacrificatceco zuen bihotzac anda aien aldare gañean. Du esaten Davidec, gure Jaincoaren vorondate benignoac edificatcen dituenean Jerusalen espiritualeco moralla destruituac, benigne fac domine in bona voluntate tua Sion, ut aedificentur muri Jerusalen, ${ }^{63}$ eztela orduan izanen ofrenda $\langle 11 \mathrm{v}\rangle$ generoric gustoz acceptatuco ez duenic, tunc acceptabis sacrificium justitiae, oblationes, et holocausta. ${ }^{64}$ Animo ona, becatariac, allegatu da ya piedade divinoac ofrecitcen digun jubileo universaleco eguna, ta hordua edificatceco animen muralla berri, culpaquin destruitua pena ta sentimentuen pechuetaco golpez. Accepta zazu, aita amorosoa, gure bihotz arrepentituen sacrificioa. Eta zuc, ama piedadez betea, barca zaguzu

61 orrec] lerro artean.

62 Becatari] esk. Bacatari.

63 benigne... muri Jerusalen: «Edertu Sion zeure mesedeaz, eraiki berriro Jerusalengo harresiak». Miserere $m e i$-ko beste pasarte bat da.

${ }^{64}$ tunc... et holocausta: «Orduan, atsegin izango dituzu legezko sakrifizioak, oso-osorik erretzeko opariak»; Miserere mei-ko pasartea, aurrekoaren jarraipena. 
zure ofenditzalleai. Zure piedadeac gara bitza ${ }^{65}$ gure venganzac, bada, gaude gucioc arrepentituac. Eta nai ganioque eman zure semeari sepultura gure entrañetan, gure bihotcetan ta gure animetan. Baña, daucazun casoan prevenitua, acompañatuco zaitugu procesioan gure beguietaco malcoaquin. An repartituco dizquiguzu, ama maitea, tocatcen zazquigun alajac. Guardatuco ditugu gure animetan eternidade gucian. Ojala gure bihotzac izaten balira Jesusen betico aldare! Esperanza daucagu zure graciarequin batean zure seme defuntuaren merecimentucgatic ${ }^{66}$ resucitatuco garala sepulturatic zucen gloriara. Ad quam nos perducat etc.

\section{Hizkuntza azterketa}

Edizioa eginda, hizkuntzaren azterketarekin jarraituko dugu orain. Bertan, grafiako (\$5.1), fonologiako (\$5.2), morfologiako (\$5.3), sintaxiko (\$5.4) eta lexikoko (\$5.5) ezaugarri nagusiak aztertuko ditugu. Helburua ezaugarri dialektalak aztertzea da, beraz, kronologikoki edo geografikoki interesgarri izan litezkeen ezaugarriak bakarrik iruzkinduko ditugu.

\subsection{Grafia}

5.1.1. Grafia aldetik, nabarmena da afrikatu eta igurzkarien bereizketa, sistematikoa baita. Bizkarkarirako <tc $>$ eta $<\mathrm{tz}>$ erabiltzen ditu; aldiz, apikariarekin <ts $>$ : tocatcen, arratsaldean, desempeñatceco, ponderatcea, ezcaitzatzula, gurutcean (3v), itceguiten (4r), arratsean, Getsemanico (4v). Inoiz ez du afrikatua idazten ozen ondoren (ik. 5.2.7).

5.1.2. Batzuetan $<\mathrm{h}>$ grafema agertzen da, balio ezberdinarekin: bihotz, bihotceco (3r), bihotzac (3v) eta antzeko beste hainbat adibidetan ez dakigu hiatoa saihesteko den ala Iparraldeko idazleen eragina den; dena den, biotcean (3r) eta biotza (9r) ere agertzen dira, $<\mathrm{h}>$ gabe. Beste batzuetan maileguak direlako izan daiteke, heritua $(3 \mathrm{r})$, horroreac $(2 \mathrm{v})$. Horrezaz gainera, $u$-ren balio bokalikoa islatzeko izan liteke $h u$ mea (4r eta passim) adibidearen kasuan.

5.1.3. Testuan ohikoa da $<\mathrm{y}>$ balio bokalikoarekin erabiltzea, ondokoak horren adibide: $y l$ (3r eta passim), Ylluntasunac (4v), yllarguia (6r, bi aldiz), yzarrac (6r), baina illundua, iduqui, iru, ilcetatic (3r).

5.1.4. Grafia etimologikoa mantentzen da zenbait hitzetan: Triumphatcen, propheta $(3 \mathrm{r})$, augmentatceco $(4 \mathrm{v})$, asumptoco $(4 \mathrm{r})$, prompto $(7 \mathrm{r})$, catholicoac $(3 \mathrm{r}$ eta passim), Esther (8v).

5.1.5. Amaitzeko $<\mathrm{x}>$ eta $<\mathrm{g}>$ grafemak erabiltzen ditu igurzkari belarra islatzeko, batez ere $i$ eta $e$ artean: exercitu (4v), exemplo (8r), baina afligitceco (4v), escogitu (3r eta passim), privilegio (4v), parage (3r), engendratu (4r). Beste bokalekin, oro har, $<\mathrm{j}>$ erabiltzen da, baina quexatu (4v eta passim) dugu; dena den azken honetan sabaiaurrekoa ere izan liteke.

\footnotetext{
65 gara bitza] esanahia "gera bitza» da, baina ez dirudi guera-ren ordezko hutsa denik; ik. lexikoaren atalean Garatu sarrera.

66 merecimentucgatic] artikulu gabe dator eskuizkribuan, baina merecimentuacgatic-en ordezko hutsa izan liteke.
} 


\subsection{Fonologia}

5.2.1. Bokalei dagokienez, aditzetako hasieran $e->i$ - gertatu da iduqui (3r eta passim) adibidean, baina sistematikoki ecus- (4r eta passim) darabil.

5.2.2. Horrezaz landara, $a u>a$ gertatu da, nazu (5r), nazula (4v eta passim) eta arpeguico (6r eta passim), arpegui (10v eta passim), arpeguia (10v) adibideek erakusten dutenez. Euskal Herriko erdiguneko eta mendebaldeko zenbait hizkeratako ezaugarria da; sermoia idatzi zen garaian, arpegi eta nazu zituzten Kardaberatzek, Mendiburuk eta Mikelestorenak. Bestalde, eu $>e$ ere gertatzen da nere ( $3 \mathrm{r}$ eta passim) eta cere $(5 \mathrm{v}, 8 \mathrm{v})$ posesiboetan. Azkenik, ei $>$ ai gertatu da edozain $(7 \mathrm{r})$.

5.2.3. Bokalekin jarraituz, $u$ bokala beste bokal baten aurrean dagoenean kontsonante bilakatzen dela dirudi, baina grafikoki bi adibidetan ikus dezakegu: gab illuna $(7 \mathrm{v})$, christabac (11r).

5.2.4. Kontsonanteetara pasatuz gero, testuan ez da hasperenik. Hala ere, hau galdu ondoren sortutako hiatoak saihesteko $-g$ - gehitu da bokal artean: ogue (3r), agoa ( $3 \mathrm{r}$ eta passim). Ezaugarri hori ezaguna da Nafarroan XVII. mendeaz geroztik: ordukoak dira honako adibideak: agotic Elizalderen 1609ko olerki sarituan eta aguâren Ezkurrarenean; agoa eta iguesi dakartza Isastik errefrauetan eta Beriainen obretan ere agertzen da ago.

5.2.5. Albokariaren eta sudurkariaren sabaikaritzea indartsua dela dirudi, bai bo$\mathrm{kal}$ ondoren, bai diptongo ondoren: illundua (3r), illuna (7v), allegatu (3r), samiña (4r), ciñan, baña (3r eta passim), baño (4v eta passim), bururaño (3r). Hitz bukaeran ere gertatzen da: samiñ, ill (6v), oñ (9v), oraiñ, matrall (10r), mutill, orañ (11r).

5.2.6. Hitz bakar batean $-r$ - $>-d$ - gertatu da idequi (4v eta passim) adibidean.

5.2.7. Grafian ikusi dugunez, afrikatuak ongi adierazten dira, baina sekula ez dira agertzen ozen ondoren. Hori dela eta, badirudi txistukaria igurzkaria zela ozen ondoren: ignoranciac (3v), Mariarenzat, emezurza, galcen, ninzan, componcen (4r).

5.2.8. Kontsonante multzoei dagokienez, $-r(t) z$ - > -st- gertatu da: ostiral (3r), onenbeste ( $5 \mathrm{r})$, beste ( $5 \mathrm{v}$ eta passim). Oro har, Nafarroako zati handienean bertze edo berze badugu ere, herrialdearen mendebaldean beste erabiltzen da.

\subsection{Morfologia}

5.3.1. Izen morfologiari dagokionez, ezezko polaritatea duen niorc (6r eta passim) izenordaina erabiltzen du. Ezaugarri honek bat egiten du iparraldeko goi-nafarrerazko beste testu zahar batzuekin: niorc du Leitzako apaizaren 1626ko auziko agiriak, nior dakar Perotxegik, eta niori eta niorc daude Bortzirietako Joseph Elizalderen gutunetan. Testu berriagoetan, nior du Etxalarko Sanzberrok eta nihorc agertzen da Baztango 1750eko eliza-aginduan. Mendiburuk eta Lizarraga Elkanokoak ere nior dute. Amenduxek ere niorc du. 1825 eko Goizuetako udal ordenantzetan ere niorc dago.

5.3.2 Artikulu hurbila fosildurik agertzen da gucioc (9v eta passim) adibidean. Bestelako testuinguruetan ez da ageri: Guc, becatariac, eranzun dezaquegu (8r).

5.3.3. Erakusleez den bezainbatez, ondoko taulan ikus dezakegu zein diren testuan lekukotzen diren hiru graduetako erakusleak absolutibo eta ergatiboan. 


\begin{tabular}{|l|l|l|}
\hline & \multicolumn{1}{|c|}{ Singularra } & \multicolumn{1}{|c|}{ Plurala } \\
\hline $\begin{array}{l}\text { 1. gradua } \\
\text { 2. gradua }\end{array}$ & au / onec & - \\
3. gradua & ori orrec & oriec \\
\hline
\end{tabular}

5.3.4. Posesiboei dagokienez, lehen pertsonan jatorriz forma indartuan den nere agertzen da beti, inoiz ez nire edo ene. Bigarren pertsonan zure agertzen da kasu gehienetan, baita indartua espero dugunetan ere. Dena den, bitan cere agertzen da, il zara cere vorondatez (5v) eta ematen duzula cere vasalloacgatic bicitza (8v). Beste bitan posesibo indartu hori oinarri hartutako destinatiboa dugu: Goarda zazu, señora, ceretzat depositutcen duzula (8v) eta Guarda zazu alaja divina ori ceretzat (10r). Azkenik, hirugarren pertsonan bere dakar. Pluralera pasatuz gero, lehen pertsonan gure eta bigarrengoan zuen posesibo arruntak erabiltzen ditu beti. Hirugarren pertsonan beren agertzen da.

5.3.5. Kasu markei dagokienez, ergatibo pluralean $-a k$ erabiltzen da:

(...) sentidoric eztuten criatura guciac ere sentidoa bailute bezala (3v)

(...) registratcen dute nere beguiac illa eriotz afrentosa batequin (5v)

(...) iru Erregue Magoac adoratu zuten zure semea Belengo portalean erregue gucien erreguetzat (8v)

5.3.6. Datiboan, -ari singularra eta -ai plurala dira atzizkiak. Ondoko adibidea horren erakusgarri garbia izan liteke: Deitcen diotelaric Eliza ama santac gurutceari eta ilceai dulceac "dulce lignum, dulces clavos", deitcen dio lanzari cruela (7v). Bizidunen kasuan, Jacoberi (6v) dugu.

5.3.7. Bizidunen kasuetan, -gan erabiltzen da sistematikoki: zugan (3v), norgana (4r) nigan (4r), Eliasgandic (4v), eternoagandic, zugandic (5r). Ez da inoiz ekialde zabaleko berrikuntza den baita-rik agertzen.

5.3.8. Goi-nafarreraren ezaugarri esklusiboa instrumentalaren aldaera apikaria bada ere, Goizuetako sermoi honetan $-z$ aldaera bizkarkaria ageri da beti, gaur egun bezala: guztiz (3r eta passim), embidiaz (3r), utsaz, lutuz, lañoz (3v), nitaz (4v).

5.3.9. Destinatiboan beti - $(t) z a t$ erabiltzen da: Mariarenzat (4r), neretzat (4v eta passim), gucienzat (5r). Ez dago ekialde zabalean, eta mendebaldeko hizkera batzuetan, agertzen den -(r)etaco edo -(r)endaco.

5.3.10. Prolatiboan ere -tzat agertzen da, hauek adibide: aliviotzat $(4 \mathrm{v})$, amatzat (6r), discipulotzat (7v), erreguetzat (8v), ez dago Nafarroan ohikoa den -taco.

5.3.11. Ablatibo mugagabe eta pluralean -etatic berria agertzen da: parage onetatic, iru iltcetatic (3r), beguietatic, beren toquietatic (3v). Ez dago -etaric zaharraren adibiderik.

5.3.12. Hurbiltze adlatiboan -(r)onz aldaera daukagu: lurreronz, beitironz $(7 \mathrm{r})$, portaleronz (7v), guganonz (9r).

5.3.13. Motibatiboan, ohi denez, -gatic erabiltzen da, baina oro har absolutiboaren gainean eraikitzen da: penagatic (8r), Vasalloacgatic (8v), zuecgatic (11 $\mathrm{r}$ bi aldiz), merecimentucgatic $(11 \mathrm{v})$ ditugu. Genitiboaren gainean eraikitako adibide bakarrak orrengatic (6v eta passim) adibidekoak dira.

5.3.14. Moduzko adberbioak sortzeko, -(r)ica erdigunean ezagun den atzizkia agertzen da, baina adibide bakarra da: chinchillica (3r, 3v). Bestela, -(r)ic arrunta da 
nagusi: recebituric (3r), urturic, despedituric (3v). Partitiboan ere beti erabiltzen da -(r)ic, besteak beste, ondoko adibideetan ikusten denez: sentimenturic, sentidoric (3v), doloreric (4r). Halaber, -ric duten moduzko adberbioen gainean eraikiak dirudite ondoko adibideek: zulaturicaco, illunduricaco, odolduricaco, urraturicaco, transpasaturicaco, atravesaturicaco (10r).

5.3.15. Handi adjektiboa mugagabean deklinatzen da nolakoa adierazten duenean:

Ha, cein honra anditaco eguna ura! Eta ha cein afrenta anditacoa au! (8v)

Testu nafarretan ohikoa da anditaco agertzea, Beriainek, Mendiburuk, Lizarraga Elkanokoak eta Hualde Maiok baitarabilte. Iparraldeko testuetan ere handitaco agertzen da. Hala ere, Goizuetako sermoi honetan amabi aranzazco lanzada afrenta andicoac (9r) ere agertzen da.

5.3.16. Ordua adierazterako iru orduetan (3r) agertzen da.

5.3.17. Denborazko adberbioen artean, ondorean $(5 \mathrm{r}$ eta $9 \mathrm{r}$ ) aldaera dugu.

5.3.18. Aditz morfologiari dagokionez, goi-nafarreraz usu agertzen diren partizipio pleonastikoak ditugu: egondu (3v), izandu (4v eta passim) baina izan ( $3 \mathrm{v}$ eta passim), jaquindu (8v), iduquitu (10r) baina bitan iduqui. Erdiguneko hizkerek egindako berrikuntza da honakoa, eta Nafarroan. XvII. mendearen hasieratik ditugu halakoak.

5.3.19. Ekialde zabaleko hizkeretan ohi denez, $-n$-z bukatzen den aditzen geroaldia egiteko -en morfema erabiltzen da: izanen ( $4 \mathrm{r}$ eta passim), egonen ( $5 \mathrm{v}$ eta passim), emanen (6v eta passim).

5.3.20. Aditz-izenak osatzeko, - $i$-z amaitzen diren aditzekin partizipioa hartzen da oinarri: assitcen (7v). Goi-nafarrerak XVII. mendeaz geroztik lekukotzen duen ezaugarria da.

5.3.21. Jokatuei bagagozkie, ${ }^{*} e d u n$-en orainaldiko erroa $-u$ - da sistematikoki: $d u t$ (3r eta passim), badugu (3v), duzu ( $5 \mathrm{r}$ eta passim), duzute (4r eta passim).

5.3.22. Halaber, izan aditzaren bigarren pertsonan orainaldian $-a$ - da erroa: zara ( $3 \mathrm{r}$ eta passim) eta zarate ( $7 \mathrm{v}$ eta passim) ditugu. Aldiz, iraganeko hirugarren pertsonan -e-dugu: cen (4r eta passim); baina ik. 5.3.23. Bestalde, orainaldiko pluraleko hirugarren pertsonako adizkia dira (3v eta passim) da, baina, behin bada ere, diradenai (10r) pleonastikoa dugu; aski ohikoa orduko eta lehenagoko goi-nafarreraz.

5.3.23. Iraganeko eta ahalerazko adizkietan, trinko zein laguntzaileetan, sistematikoki -a-dago: zacarren $(4 \mathrm{v})$, zanidanean, $(5 \mathrm{v})$, zanutenac $(7 \mathrm{r})$, zagoen $(8 \mathrm{v})$, zanuena $(7 \mathrm{r}, 9 \mathrm{r}, 10 \mathrm{r})$, zanigun $(10 \mathrm{v})$, zanuen $(10 \mathrm{r})$, ezpalago $(10 \mathrm{v})$, ganioque (11v). Bestalde, iraganeko adizkietan -an dago bukaeran: ninzan, ciñan, etciñan (4r eta passim), baina beti da cen (4r eta passim).

5.3.24. Goi-nafarrerako testuetan ohi denez, egon aditzaren forma trinkoetan zauten (8r), zautenac (8v) dugu bigarren pertsona pluralean. Bestalde, NOR-NORI erregimenean ere erabiltzen da egon: dagocan $(3 \mathrm{v})$ eta dagoquit (5v). Azkenik, joan aditzaren dijoa $(9 \mathrm{v})$ erabiltzen da.

5.3.25. Era berean, eduki aditzaren forma jokatuetan pluralgilea $-z k i$ da: zauzquien $(8 \mathrm{v}, 10 \mathrm{r})$, dauzquien $(9 \mathrm{v})$. Ezaugarri hau goi-nafarreraren lehen lekukotasunetarik ageri da, eta dialektoaren eremu osoa hartzen du.

5.3.26. Aditz laguntzaileetara pasatuz gero, N-N-N saileko indikatiboan *nin eta *eradun agertzen dira, baina lehena da nagusi. * Eradun NOR plurala eta NORK hirugarren pertsona denean bakarrik erabiltzen da. Hauek dira adibideak: uca- 
tcen derazquiola (3v), bidaldu cerazquizun, ematen cerazquiola (4v), pagatu derazquitzu (9r).

5.3.27. Perifrasi berarekin jarraituz, aurrekoan ikusi dugun bezala, *eradun da $\mathrm{N}-\mathrm{N}-\mathrm{N}$ saileko pluraleko laguntzaile nagusia, eta hor pluralgilea $-z k i-\mathrm{da}$ beti. Aldiz, *nin laguntzaileari dagokionez, NOR pluralaren bi adibide ditugu eta $-z k i$ - eta -it-, biak agertzen dira: etcenitidan (4r), dizquiguzu (11v).

5.3.28. NOR-NORI sailean, tocatcen zaizcan $(7 \mathrm{v})$ adibidean ikus dezakegunez, -zkadugu pluralean. Adizki hau dute, besteak beste, Otxoa Arinek, Larramendik, Kardaberatzek, Ubillosek eta Mendiburuk ere.

5.3.29. Pluralez ari garela, aipatzea merezi du -te pluralaren hedadura zabala. Oro har, goi-nafarreraz -te pluralgilea NOR-NORK eta NOR-NORI-NORK sailetako NORK kasuko hirugarren pertsona pluralari dagokio, Goizuetan bezala: dute (5v eta passim), diote ( $3 \mathrm{r}$ eta passim). Dena dela, goi-nafarrerakoak diren hizkera batzuetan, batez ere, Gipuzkoako ipar-ekialdean eta Goizuetan, pluralgilea, analogiaz-edo, NORK bigarren pertsonara ere hedatu da: eguizute (3r), zazute ( $3 \mathrm{r}$ eta passim), duzutenac ( $4 \mathrm{r}$ eta passim). Kasu batzuetan datiboko 'haiei' pertsonari dagokio diotelaric (7v) 'harkhaiei' baita, Eliza ama santac da subjektua eta gurutceari eta ilceai datiboa. "Zukhaiei» den zaiozute ( $7 \mathrm{r}$ eta passim) ere ageri da.

Pluralgilearen hedadura hau XvIII. mendetik aurrerakoa dela dirudi, 1633ko Goizuetako esaldi batean didazue agertzen baita.

5.3.30. Indikatiboaz landako perifrasietan, aditzoina eta partizipioaren erabilerak merezi du aipamenik. Itxura batean bereizketa sistematikoa dela dirudi, eta aditzoina erabiltzen da -tu-z bukatzen den aditzekin: bana zazu, ezcaitzatzula arren desampara, lagun zaguzu, asisti zaguzu, obliga dezagun, ez dezaquet gueiago continua (3v), servi ciezaion (4v), etcezan pesadumbrez bicitza galdu, gal dezaqueanic (6v). Aldiz, zalantza dago - $i$-z bukatzen denekin, adibide garbiak dira ondokoak: ecus dezaten (8r), icas dezaten (9v), ecus dezaten (10v). Salbuespenik ez da falta ordea: Ytzuli zazu, itzuli zazu (7r) eta, beharbada, Ytzuli tzatzu, itzuli tzatzu (7v, bi aldiz). Gainera, Lotu zazute (8r), leitu zazu (8v), eztezaquezu ezagutu (10r) ere badira.

5.3.31. Ahalerazko kasuetan, izan aditzaren formetan -que baliatzen da eta ez -teque pleonastikoa: lizaque (6r, 10v).

5.3.32. Indikatiboaz landa, entrega bequitza (7v) adibidean NOR-NORI sailean, inpertsonalean, ${ }^{*} e d i n$-en adizkia bide dugu laguntzailea, -tza pluralgilearekin. Ez dugu adizki hau beste inon aurkitu. Singularrean entrega bequio (8v) dago. Bestalde, sail berean, iguala daquicoanic (4r) ageri da; Beriainek ere daquico eta $d a-$ quioque ditu.

5.3.33. NOR-NORK sailean aginterazko perifrasietan, subjektua bigarren pertsona denean eta objektua hirugarren pertsona pluralekoa, (i)tzatzu eta $t c i z u(t e)$ ageri dira. Lehena hirutan ageri da, eta guztietan -i partizipioa duen aditzeko: Bidali tzatzu $(7 \mathrm{r})$, Ytzuli tzatzu, itzuli tzatzu (7v). Bigarrena maizago ageri da, sei aldiz, eta guztietan -tu bukaerako aditzak dira: bera tcitzu, inclina tcitzu (7r), esca tcitzute (8r), coroa tcitzute (9r), prepara tcitzu (10v, bi aldiz) gisako formak ditugu. Objektua hirugarren pertsonako singularra denean, $z a z u$ ( $3 \mathrm{v}$ eta passim) agertzen da.

5.3.34. NOR sailean, jusiboko adizkien artean *edin aditzaren beitez $(7 \mathrm{r}, 9 \mathrm{v})$ adizki diptongoduna dugu. 
5.3.35. Indikatiboaz landako NOR-NORI-NOR sailean, hari hirugarren pertsona denean, servi ciezaion (4v) dugu, dative flag edo datibo aurrekoa delakoarekin.

5.3.36. Aferesidun aditz laguntzaileak ditugu aginterazko perifrasietan: lagun $z a-$ guzu, asisti zaguzu (3v), itzuli zazu (7r), Lotu zazute (8r), leitu zazu (8v), eracutsi zaguzu (10v).

\subsection{Sintaxia}

5.4.1. Sintaxiaz den bezainbatean, sermoi honetan bi aldiz agertzen da "Xrekin Y» egitura kopulatiboa: agoan beazumarequin vinagrea (3r), gurasoarequin humearequico amorioa (4r). Euskal testu zaharretan gisa honetako egiturak agertzen diren arren, goi-nafarreraren kasuan oso bakan agertzen dira. Lekukotasun honen aurretik, XvII. mende bukaerako Joseph Elizalderen gutunetako batean bakarrik aurkitu dugu; hala ere, ahozko tradiziotik jasotako kantuetan agertzen dira halakoak.

5.4.2. Aditz izenekin absolutiboa erabiltzen da, ez da TO-GEN ageri:

(...) nere ignoranciac desempeñatceco (3v).

(...) edozain maldade executatcera $(7 \mathrm{r})$.

(...) zure pena andiac aliviatcera $(7 \mathrm{v})$.

5.4.3. Perpaus osagarrietan atzizkiaren aldaera -ela eta -ala, biak agertzen dira: dela, dituela (3r eta passim), zuela (6v), baina ciñala (4v), zarala $(5 \mathrm{r}, 8 \mathrm{v})$ naizala $(5 \mathrm{v}$ eta passim), dirala (6r).

5.4.4. Egoera antzekoa bide da erlatibozko perpausetan ere, -en eta -an bi aldaerak agertzen baitira: zaran $(5 \mathrm{r}, 10 \mathrm{v})$, daitequeanic (6v), baina den (4r eta passim), dituen ( $3 \mathrm{r}$ eta passim). Gisa berean, zaran bezala $(5 \mathrm{r})$ eta zaran casoan (10v) adibideetan adizkiek bukaeran -an dute.

5.4.5. Kausazko perpausetan cergatic ... -an egitura ageri da: cergatic naizan zure alaba bacarra (5r), cergatic naizan Christoren, justiciaren, eguzqui divinoaren ama (6r), baina salbuespenik ere bada: cergatic bereala etorrico dira eta emanen diote sepultura $(6 \mathrm{v})$.

Horrekin batera, bait- ere ageri da: baitzara nere aita (5r), baita ceruco atea eta misericordiaren ama (9r).

5.4.6. Aresti-Linschmann legeari dagokionez, lehen pertsonarekin ez da gertatzen, beti nere erabiltzen baita. Bigarren pertsonan zure agertzen da kasu gehienetan, baita legearen arabera indartua espero dugunetan. Dena den, bitan cere agertzen da, il zara cere vorondatez (5v) eta ematen duzula cere vasalloacgatic bicitza (8v). Beste bitan posesibo indartu hori oinarri hartutako destinatiboa dugu: Goarda zazu, señora, ceretzat depositutcen duzula (8v) eta Guarda zazu alaja divina ori ceretzat (10r); bietan betetzen da Aresti-Linschmann legea. Azkenik, hirugarren pertsonan beti bere forma indartua dakar. Pluralera pasatuz gero, ez da lehen eta bigarren mailako forma indarturik ageri, ezta legearen arabera indartua behar lukeen lekuan: badugu motivoa gure bihotzac sentimentuz urturic despeditceco. Hirugarren graduan beti dugu beren indartua.

5.4.7. Testuak sintaxi aldetik duen ezaugarri nabarmenetarikoa da aditz laguntzailearen hurrenkera, maiz horiek aditz nagusiaren ezkerretara baitaude, ondoko adibideetan ikus daitekeen bezala: cergatic duen bezala Bernardo dulceac advertitcen (4r), ecetz dute eranzuten $(8 \mathrm{v})$, baiez du eranzuten ceruco erreguiñac $(10 \mathrm{v})$, dit aguincen $(11 \mathrm{r})$. 
5.4.8. Ezaugarri zaharra da -ra behar egitura; sermoian behin agertzen da: cerura bear dutenen asentua (9r). Antzeko adibidea, baina behar gabe, da ondoko adibidea ere: Nora da zure seme Jaincoa? (3r).

5.4.9. Bestalde, iruditu aditzak eskatzen duen osagarria instrumentalean dago: Cer iduritcen zaitzute tormentu cruel orietaz (8r), Cer iduri zaitzu ain beste ingratitudez (11v). Osagarrien atzizkiekin jarraituz, perpaus osagarrietan -tera dugu, ez -teko: prompto egonen da edozain maldade executatcera $(7 \mathrm{r})$.

5.4.10. Desirazko perpausak osatzeko, ez dezazula arren nai izan $(7 \mathrm{r})$ agertzen da, baina ojala duen perpaus bat ere bada: Ojala gure bihotzac izaten balira Jesusen betico aldare $(11 \mathrm{v})$.

5.4.11. NZ gisako galderetan al partikula erabiltzen da, baina beti ahalerazko aditzekin. Beraz, ahalerari loturik ulertu behar, ez galde partikula bezala: nola iduqui al dezaque bere ama maitearena? (3r), Cer eguin al dezaque gucia galcen duenac? (4r), cer eguin al dezaquet? (5r). Dena den, galderetatik kanpo ahaleran ez da al agertzen. Gipuzkeraz Kardaberatzek badu halako adibiderik ere:

Estura onetan zer egin al dezaket?

Zer egin al dezaket, bada, estu onetan?

Zer egin al dezaket nik, espada zure aurrean arritu, humillatu, tan ere biotzeko ateak zuri pozik idiki?

Zer esan al dezaket nik zure aurrean, neronek baño obeto nere gaitza zure begiak badakuste?

Aztergai dugun sermoian zehar-galdera batean ere agertzen da partikula hori: Guardazazu alaja divina ori ceretzat, baduzu experiencia gure ingratitudeac cer eguin al dezaquean (10r).

NZ izan arren, aditza ez bada ahalerazkoa, ez da al partikula agertzen, ondoko adibidean ikus dezakegunez: Nora da zure seme Jaincoa? (3r). Halaber, ez da partikularik Bai/Ez erako galderetan: etcinan zu nere aita?; ez ninduzun zuc zure providencia divinoarequin ni sustentatcen? (4r).

5.4.12. Moduzko mendeko perpausetan - (e)laric eta - (e)la erabiltzen dira:

(...) eta tocatcen zaiolaric gaur arratsaldean nere oztasunari (...) ponderatcea zure soledadea (...) (3v).

Bada, nere aita, nola falta zait niri alivio ta consuelo gucia bici naizalaric ain desamparatua ta bacarra? (4v).

(...) uzten nazula bicitzaquin ain desamparatua padecitceco? (4v)

Era berean, moduzko perpausa da ondoko adibidea ere, bait... bezala egiturarekin:

(...) criatura guciac ere sentidoa bailute bezala sentimentuaren eta penaren pasioz nai luquete acabatuac izan (...).

Asco ezpailiz bezala semeric bague desamparatua guelditcea, nai izandu duzu gueiago nere beguiz ecus zaitzadan.

5.4.13. Uste izan behin bakarrik agertzen bada ere, ezezkoa da eta -ela agertzen da:

Ez dut uste gaur, zure gracien iturri guciac idequiagoac dauden temporan, ucatuco didazula desempeñatceco gracia 


\subsection{Lexikoa}

Lexiko aldetik kronologikoki zein geografikoki interesgarri diratekeen hitz eta aldaerak aipatu eta batzuk iruzkinduko ditugu, iturri nagusitzat $O E H$ hartuta, hurrenkera alfabetikoan:

Ai: ay (3v, 5v). 'Auhen'.

Alaja: alaja $(4 \mathrm{v}, 7 \mathrm{v}, 9 \mathrm{r}, 10 \mathrm{r}, 11 \mathrm{v})$. 'Bitxia'; Larramendi bide da mailegu hau jasotzen duen lehena.

Anda: anda (11r). 'Zerraldo'.

Atzeneko: atceneco (3r), atcenecoa (5v). 'Azkeneko'.

Atzendu: atzenduric (8r).

Asnase: asnasea, asnase (3r). 'Arnasa'; Larramendi bide da aldaera hau jasotzen lehena.

Bage: bague (3v eta passim). 'Gabe'; goi-nafarrera zaharrean Beriainek, esaterako, aldaera hau darabil. 1633ko Goizuetako esaldi batean ere bague dugu.

Bearri: bearrietan (3r). 'Belarri'; Iparraldean eta Nafarroan erabiltzen den aldaera bide da.

Beazuma: beazumarequin (3r). 'Behazun'.

Beratx: beracha (3r), barach (9v). 'Samur, leun'.

Emezurtz: emezurza (4r eta passim). 'Emazurtz, umezurtz'; Euskal Klasikoen Corpusean bilaketa eginda, emezurtz aldaera bi bider agertzen da, baina biak Kardaberatzen idatzietan. Materrak emazurtz dakar.

Esan: esan ( $7 \mathrm{r}$ eta passim): Nafarroako mendebaldean bezala, esan erabiltzen da, ez erran.

Garatu: gara bitza (11v). 'Geratu'; OEHren arabera, zaraitzuerazko eta erronkarierazko aldaera da.

Geroen: gueroena (4v). 'Azkenik'. OEHn ez dugu geroen aurkitu, baina geroenean eta geroenez agertzen dira.

Idero: iderotcen $(3 \mathrm{r}$ eta passim), idero $(4 \mathrm{v}, 9 \mathrm{v})$, iderotcea $(4 \mathrm{v})$, ideroco $(7 \mathrm{r}, 7 \mathrm{v})$. 'Ediren'; partizipioan aldaera hau lekukotu gabe egon da orain arte, baina $R S \mathrm{n}$ ideraiten agertzen da, Lazarragaren eskuizkribuko B testun ideraite dugu. Areago, iderotcen Goizuetako 1825 eko ordenantzetan.

Ideki: idequitcen (3v), idequiagoac (3v), idequi (4v eta passim), idequiric (7v), idequico (7v). 'Ireki'; Bortzirietako eta Iparraldeko aldaera bide da.

Ikarari: icarariac (3r). 'Dardara'.

Istu: istuac (3r), Ystu (10r). 'Listu'.

Itsi: itsia (7r, 9r). Aldaera apikariduna dute, besteak bestel, RSk, Lazarragak, Landuccik, Mendiburuk eta Lardizabalek.

Izertu: icercen (4v). 'Izerditu'.

Katabut: catabura (9v). 'Hilkutxa'. Larramendik eta Kardaberatzek ere katabut erabiltzen dute.

Matrail: matralletan (3r), matrall (10r). 'Masaila'.

Nahi: nic nahi nizun zuri esposa agradecituac bezala (5r). 'Maitatu, deseatu' zentzuan ere erabiltzen dela dirudi, eta $\mathrm{N}-\mathrm{N}-\mathrm{N}$ saileko laguntzailearekin.

Santu: santu (3r), santuco (3v), santua (5r eta passim), santuac (5r, 8r), santuarequin $(7 \mathrm{r}, 8 \mathrm{v})$, santu $(7 \mathrm{r})$. Ez da goi-nafarreraz erabili ohi den sandu agertzen.

Solbarda: solbardan (3r). 'Sorbalda'; aldaera hau lekukotzen lehena Larramendi bide da; fray Bartolomek eta Añibarrok ere aldaera hau dute. 
Tempora: temporan $(3 \mathrm{v}, 8 \mathrm{v}, 9 \mathrm{v})$, tempora (6v). Sermoian lau aldiz hasiera ahoskabearekin agertzen da, eta behin dembora (6r). Azken aldaera orokorraz gain, Gipuzkoan tempora erabili zuten Isastik, Otxoa Arinek, Erauskinek, Irazustak eta behin Mendiburuk, eta aldaera bera agertzen da Zegamako dotrinan ere.

Trunku: truncu (8v). OEHn aezkerako, zaraitzuerako eta erronkarierako aldaeratzat dator (s.v. tronko). Dirudienez, gurutzerari egin diezaioke erreferentzia.

\section{Ondorioak}

Artikulu honetan euskal testu zaharren corpusari ekarpena egin nahi izan diogu, eta horretarako 1753an idatzitako sermoi baten edizioa aurkeztu dugu.

Edizioarekin batera, bertako hizkera ere aztertu dugu: baiezta dezakegu goi-nafarrerazko lekukotasun orain arte ezezagun bat dugula esku artean. Ez dugu zuzenean Goizuetako euskararekin sistematikoki erkatu, baina ez dirudi bertakotzat hartzeko zailtasun handirik dagoenik.

Zalantzarik gabe, merezi luke konparaketa zehatz eta sakonagoa egitea, baina 1825 eko Goizuetako udal-ordenantzekin (Satrustegi 1996) erkaturik hizkera beraren aurrean gaudela pentsatzeko arrazoiak ditugu: goi-nafarrerako dauzki 'dauzka' gisako adizki nafarrak ageri dira bietan, baina instrumentalean $-z$ orokorra, ez $-s$ nafarra. Gainera, -te pluralgilearen hedadura, egun bezala, zabala da ordenantzetan ere: zaiotela eta zaioten agertzen dira bertan. 1753 eta 1825 eko Goizuetako bi testu hauetan ergatibo plurala -ac da, eta edozain eta niorc ageri dira bi horietan, baina edocin eta iñorc 1897 koan.

Bistan denez, hemen ez dugu, inolaz ere, testuen arteko konparaketa sakonik egin, baina, esan dugunez, sermoiaren estilo jasoa gorabehera, Goizuetako euskaraz idatzita dago. Dena den *eradun aditza laguntzailea ez bide da lekukotzen beranduago Goizuetan, eta gauza bera gertatzen dela dirudi sistematikoki iraganean - $a$ duten aditzekin ere.

\section{Bibliografia}

Bernardo Clairvauxkoa, [s.a.], «Opusculo duo», in Marco Binetti (arg.), S. Bernardi Claraevallensis Opera omnia [online]. http://www.binetti.ru/bernardus/26.shtml [Azken kontsulta: 2016/03/14].

Bilbao, G., 2013, "Textos Arcaicos Vascos 50 urte beranduago» in R. Gómez, J. Gorrochategui, J.A. Lakarra \& C. Mounole (arg.), 2013, Koldo Mitxelena Katedraren III. Biltzarra - III Congreso de la Cátedra Luis Michelena - $3^{\text {rd }}$ Conference of the Luis Michelena Chair, UPV/EHU, Gasteiz, 717-728.

- et al., 2010, Lazarraga eskuizkribua: edizioa eta azterketa (1.0), Vitoria-Gasteiz, UPV/ EHU, <http://lazarraga.com> [Azken bisita: 2016/03/16].

— \& R. Gómez, 2014, "Textos antiguos vascos en Internet», in S. López Poza \& N. Pena Sueiro (arg.), Humanidades Digitales: desafios, logros y perspectivas de futuro, Janus, Anexo 1 (2014) [on line], Universidade da Coruña, A Coruña, 111-121. Interneten eskuragarri: <http://www.janusdigital.es/anexos/contribucion.htm?id=11>.

Lekaroz, G., 2006, "Antzinako baztanera: xviı. mendeko prediku argitaragabe bat», FLV 101, 69-94.

—, 2014, «Basaburu Txikiko euskararen lekukoak (I)», FLV 118, 247-278.

—, 2015, «Basaburu Txikiko euskararen lekukoak (eta II)», FLV 120, 277-324. 
Los Arcos, J.L., 1974, «Glosas en el dialecto navarro al «Guero» de Axular», FLV 16, 39-84.

Ondarra, F., 1981, «Primer sermón en vascuence navarro (1729)», FLV 38, 147-173.

—, 1989, «Goñerrin aurkitutako sei euskal testu (1743-1753)», FLV 53, 97-144.

—, 1993a, "Hemezortzigarren mendeko bertsoak», FLV 64, 531-553.

—, 1993b, «Goñerrin aurkitutako testuak (IX)», ASJU 27-1, 299-320.

—, 1993c, "Goñerrin aurkitutako testuak (X)», ASJU 27-3, 903-948.

—, 1994, «Goñerrin aurkitutako testuak (VI)», FLV 67, 521-554.

—, 1995, «Gońerrin aurkitutako testuak (VII)», FLV 68, 173-190.

_, 1996a, «Juan Martin de Ibero (1729-1783), Izuko parrokua (1754-1783)», FLV 72, 235-267.

—, 1996b, «Juan Martin de Ibero (1729-1783), Izuko parrokuaren testuak (I)», ASJU 30-1, 645-702.

—, 1998, «Juan Martin de Ibero (1729-1783), Izuko parrokuaren testuak (II)», ASJU 32-1, 231-309.

Orduna, G., 1990, "La "edición crítica”", orain in Orduna, 2005, Fundamentos de crítica textual, Arco/Libros, Madril 17-38.

Prada Santamaria, A.; J.L. Sales Tirapu \& J.Á. Garro Mujika, [s.a.], Libro del Obispado de Pamplona. Real Patronato 1753 [pdf]. Sarean eskuragarri: http://mendezmende.org/documentos/divulgacion_trabajos/LIBRODELOBISPADODEPAMPLONA.pdf [Azken kontsulta: 2016/02/06].

Satrustegi, J.M., 1987, Euskal Testu Zaharrak I, Euskaltzaindia, Iruñea.

—, 1996, "Goizuetako udal-ordenantzak», FLV72, 297-316.

Ulibarri, K., 2015, Dotrinazko Sermoitegia: galduriko hizkerak eta dialektologia historikoa, UPV/EHUko doktorego tesi argitaragabea.

Zuloaga, E., 2010, «Nerbioi ibarreko euskara XvIII eta XIX. mendeetan: (i) Bizente Sarriaren bizkaierazko sermoiak», ASJU 44-2, 393-435.

—, 2011, «Nerbioi ibarreko euskara XVIII eta XIX. mendeetan: II. Juan Ignazio Astigarragaren sermoi-bilduma», $A S J U$ 45-1, 235-276.

Zubiri, J.J., 2000, "Arano eta Goizuetako hizkera» in K. Zuazo (arg.), 2000, Dialektologia gaiak, Arabako Foru Aldundia, Gasteiz.

Urtzi Reguero Ugarte (UPV/EHU)

Hizkuntza eta Literaturaren Didaktika Saila

Hezkuntza eta Kirol Fakultatea

Juan Ibáñez de Sto. Domingo kalea, 1

01006 - VITORIA-GASTEIZ

Tel: 945014200

urtzi.reguero@ehu.eus 